\title{
Reactive Oxygen Species and Inhibitors of Inflammatory Enzymes, NADPH Oxidase, and iNOS in Experimental Models of Parkinson's Disease
}

\author{
Sushruta Koppula, Hemant Kumar, In Su Kim, and Dong-Kug Choi \\ Department of Biotechnology, Research Institute of Inflammatory Diseases, Konkuk University, Chungju 380-701, Republic of Korea \\ Correspondence should be addressed to Dong-Kug Choi, choidk@kku.ac.kr
}

Received 3 November 2011; Revised 23 December 2011; Accepted 9 January 2012

Academic Editor: Luc Vallières

Copyright (C) 2012 Sushruta Koppula et al. This is an open access article distributed under the Creative Commons Attribution License, which permits unrestricted use, distribution, and reproduction in any medium, provided the original work is properly cited.

Reactive oxygen species (ROSs) are emerging as important players in the etiology of neurodegenerative disorders including Parkinson's disease (PD). Out of several ROS-generating systems, the inflammatory enzymes nicotinamide adenine dinucleotide phosphate $(\mathrm{NADPH})$ oxidase and inducible nitric oxide synthase (iNOS) were believed to play major roles. Mounting evidence suggests that activation of NADPH oxidase and the expression of iNOS are directly linked to the generation of highly reactive ROS which affects various cellular components and preferentially damage midbrain dopaminergic neurons in PD. Therefore, appropriate management or inhibition of ROS generated by these enzymes may represent a therapeutic target to reduce neuronal degeneration seen in PD. Here, we have summarized recently developed agents and patents claimed as inhibitors of NADPH oxidase and iNOS enzymes in experimental models of PD.

\section{Introduction}

Brain inflammation may contribute to a wide variety of neurodegenerative pathologies. Major regulators of brain inflammation that may exert a direct effect on neurons are reactive oxygen species (ROSs). ROSs are emerging as important players in the etiology of neurodegenerative disorders [1]. Due to the reduced capacity of neuronal regeneration and high metabolic rate, the brain is believed to be profoundly liable to the damaging effects of ROS and the dopaminergic neurons in the substantia nigra of Parkinson' disease (PD) patients are undoubtedly susceptible. Different data sets suggest that oxidative stress is at the center of various neurodegenerative diseases. Postmortem brain tissues from patients with neurodegenerative diseases including Alzheimer's disease (AD), PD, Huntington's disease (HD), and amyotrophic lateral sclerosis (ALS) clearly show increased levels of ROS in affected brain regions [2-4]. Though one cannot assume that only ROSs are the major cause of these disease states, it is necessary to question what is responsible for this increased ROS generation.
ROSs are a wide range of small signaling molecules which are highly reactive unpaired valence electrons. ROSs include superoxide $\left(\mathrm{O}_{2}{ }^{-}\right)$, hydrogen peroxide $\left(\mathrm{H}_{2} \mathrm{O}_{2}\right)$, hydroxyl radical $\left(\mathrm{OH}^{*}\right)$, and peroxynitrite $\left(\mathrm{ONOO}^{-}\right)$[5]. Although ROSs have some biological advantages, excessive generation may lead to threatened homeostasis of the biological system [69]. ROSs are constantly generated through a variety of pathways, including both enzyme-catalyzed reactions and nonenzyme reactions [10]. Whenever the balance between ROS generation and the natural antioxidant defense system is lost, a series of events may occur deregulating cellular functions which may lead to various pathological conditions for almost all vital organs [11]. ROS can react with vital cell components and alter intrinsic membrane properties like fluidity, ion transport, loss of enzyme activity, protein cross-linking, inhibition of protein synthesis, and DNA damage ultimately resulting in cell death [12].

A more direct effect on neurons is the ROS produced by the activation of the several inflammatory enzymes such as nicotinamide adenine dinucleotide phosphate (NADPH) oxidase, the expression of the inducible nitric oxide synthase 
(iNOS), myeloperoxidase, lipoxygenase, and cyclooxygenase (COX). These enzymes contribute to the pathogenesis of various neurodegenerative diseases including PD. Earlier studies postulated that NADPH oxidase and iNOS are not expressed in normal CNS conditions, but in PD patients and in 1-methyl-4-phenyl-1, 2, 3, 6-tetrahydropyridine (MPTP) intoxicated mice. Both are clearly expressed and activated in glial cells in the ventral midbrain. These two major inflammatory enzymes that produce ROS may have a pathogenic role in PD, because when they are lacking in mutant mice, they show less loss of dopaminergic neurons [13-15].

In this paper, we discuss recent inhibitors of ROS-generating inflammatory oxidative enzymes, in particular the NADPH oxidase and iNOS as a therapeutic strategy for the treatment of PD. We also summarize claims by recent patents for several agents as potential NADPH oxidase and iNOS inhibitors.

\section{Reactive Oxygen Species and PD}

$\mathrm{PD}$, the second most major neurodegenerative disease after $\mathrm{AD}$, is a pathological condition characterized by the degeneration of dopaminergic neurons in the substantia nigra pars compacta and loss of striatal dopamine content [16, 17]. Although several pathogenic hypotheses have been proposed for PD, oxidative stress via the generation of ROS is considered one of the major contributors. Evidence for the role of ROS was first observed in human PD brains showing mitochondrial dysfunction and oxidative damage in the degenerating areas including the substantia nigra $[18,19]$. Dopamine is a relatively unstable molecule subject to hydroxyl radical attack that can induce ROS damage both from within and outside the cell [20]. ROS generated from mitochondrial and/or extramitochondrial sources appear to be the main contributor of oxidative stress-mediated neurodegeneration in PD models [16, 21-27]. Importantly, generation of ROS from toxicity induced by accumulation of $\mathrm{MPP}^{+}$in the inner mitochondrial membrane, disruption of complex I in the electron transport chain, and interaction of $\mathrm{MPP}^{+}$with iron stores within the pigmented substantia nigra cells are the known sources of oxidative stress [28-31].

Increasing evidence indicates that inflammatory-activated microglia and astrocytes are considered to be a consequence of neuronal cell death in AD, PD, HD ALS, and multiple sclerosis [32-36]. Activated microglia highly expresses several enzymes including iNOS, NADPH oxidase, COX-2, and myeloperoxidase responsible for inflammatory processes mediated by oxidative stress. These enzymes contribute to the pathogenesis of various neurodegenerative diseases [13, 37-39]. ROS-generating multimeric enzymes are indispensable for protecting the host against infections and injuries. Inappropriate activation of these enzymes may be harmful in noninfectious neurodegenerative disorders [40, 41]. Thus, the discovery of various novel agents that inhibit the activation of these enzymes may prove to be a therapeutic strategy in ameliorating various neurodegenerative diseases including PD.

\section{Role of NADPH-Oxidase-Derived ROS Signaling in PD}

Epidemiological studies suggest that inflammation increases the risk of developing PD [42]. Several studies revealed that a significant source of ROS generated during inflammation was by NADPH oxidase. Nervous system cells contain the NADPH oxidase complex, which, when assembled and activated, produces free radicals in abundance that can lead to tissue damage [43]. NADPH oxidase which is composed of gp91 9 phox, p6 $7^{\text {phox }}$, p47 $7^{\text {phox }}, \mathrm{p} 40^{\text {phox }}$, and p22 $2^{\text {phox }}$ subunits was first studied because of its essential role in host defense [44]. In resting brain cells, NADPH oxidase is inactive because $\mathrm{p} 47^{\text {phox }}, \mathrm{p} 67^{\text {phox }}$, and $\mathrm{p} 40^{\text {phox }}$, which are present in the cytosol as a complex, are separated from gp91 ${ }^{\text {phox }}$ and p22 $2^{\text {phox }}$, which are transmembrane proteins. Upon activation, the p47phox subunit gets phosphorylated and translocates to the membrane as a complex to assemble with gp91 ${ }^{\text {phox }}$ and $\mathrm{p} 22^{\text {phox }}$ to form an active NADPH oxidase capable of reducing oxygen to a superoxide radical $\left(\mathrm{O}_{2}{ }^{-}\right)$to generate microglial and/or extramitochondrial-derived ROS [45-48].

Brain regions that are rich in catecholamines, such as adrenaline, noradrenaline, and dopamine, are also exceptionally vulnerable to free radical generation. Catecholamines can spontaneously break down to free radicals or be metabolized to free radicals by endogenous enzymes such as monoamine oxidases. Activated microglia also contribute to the degeneration of dopaminergic neurons by releasing neurotoxic factors such as NADPH-oxidase-derived superoxide and cytokines [49]. Activated microglia can produce a host of toxic molecules including reactive nitrogen species and ROS. Microglia in the vicinity of dopaminergic neurons in disease appears to have an upregulated capacity for ROS production due to increased expression of NADPH oxidase. Release of aggregated and nitrated $\alpha$-synuclein from dying or damaged dopaminergic neurons in the $\mathrm{SN}$ is thought to contribute, in part, to their activation [50, 51 .

Additionally, neurons in the vicinity of activated microglia may thus be exposed to NADPH-oxidase-derived $\mathrm{O}_{2}{ }^{-}$ and other secondary oxidants, such as $\mathrm{H}_{2} \mathrm{O}_{2}$. NADPH oxidase can be quickly activated to elevate the level of ROS within a few minutes after stimulation by a variety of growth factors, such as cytokines and hormones including interleukin (IL)-1 [52], platelet-derived growth factor (PDGF) [53], or nerve growth factor (NGF) [54].

Several studies indicated that NADPH oxidase has been linked to microglia-derived oxidative stress from a variety of neurotoxic insults, such as rotenone [55], diesel exhaust particles [56], $\alpha$-synuclein [50], amyloid beta [57], paraquat [58], dopamine neuronal injury [13, 59], and cerebral ischemia-reperfusion injury [60], indicating that microglial NADPH oxidase activation may also be a common denominator of microglial activation associated with neurotoxicity. 


\section{NADPH Oxidase Inhibitors and Experimental Models of PD}

It is well documented that NADPH oxidase is upregulated in PD [13]. Reports reveal that NADPH-oxidase activation plays a critical role in the degeneration of dopaminergic neurons and inactivation of this enzyme may be a promising target for PD treatment $[13,55,61]$. Reports also suggest that microglial toxin, LPS-induced loss of nigral dopaminergic neurons in vivo and in vitro, was significantly less pronounced in NADPH-oxidase-deficient mice, when compared to normal control mice [62]. In the normal CNS, NADPH oxidase is quiescent, but, in patients with PD and in MPTPintoxicated mice, NADPH oxidase is clearly expressed and activated in glial cells in the ventral midbrain. Thus, agents that inhibit NADPH oxidase activation may be ideal therapeutic agents for the management of PD. Here, we summarize a list of recently published and patented compounds which act as NADPH-oxidase-derived ROS inhibitors in experimental animal models focusing on PD pathology.

Ethyl pyruvate (EP, Figure 1(a)) is an effective scavenger of ROS, especially hydrogen peroxide, by virtue of its nonenzymatic oxidative decarboxylation reaction. EP has been reported to exert pharmacological effects, such as scavenging of ROS, suppression of inflammation, inhibition of apoptosis, and support of cellular ATP synthesis. Recently, EP has been shown to rescue nigrostriatal dopaminergic neurons by regulating glial activation in an MPTP intoxicated mouse model of PD. A single injection of EP (10, 25, and $50 \mathrm{mg} / \mathrm{kg}$ body weight) per day administered to mice into the peritoneum at $12 \mathrm{~h}$ after the last MPTP injection exerted neuroprotection which was associated with suppression of NADPH-oxidase-derived ROS production by activated microglia [63].

Aminoethyl-benzenesulfonylfluoride (AEBSF, Figure 1(b)), an NADPH oxidase inhibitor, was reported to be useful in ameliorating oxidative stress and apoptosis in mesencephalic dopaminergic neuronal cells. AEBSF at $300 \mu \mathrm{M}$ significantly blocked 1-methyl-4-phenylpyridinium ion$\left(\mathrm{MPP}^{+}\right.$) induced ROS production for over $45 \mathrm{~min}$ in N27 cells in a dose-dependent manner and rescued the cells from apoptotic cell death. The study supported that NADPH oxidase play a critical role in the oxidative damage in $\mathrm{PD}$ and inhibiting this enzyme activation by AEBSF may lead to novel therapy for PD [61].

Apocynin (4-hydroxy-3-methoxyacetophenone, Figure 1(c)), a selective inhibitor of NADPH-oxidase, can block the production of superoxide and oxygen-free radicals that typically accompany inflammation. Apocynin is a compound originally isolated from the medicinal plant Picrorhiza kurroa, which inhibited both intracellular and extracellular ROS production by interfering with the phagosomal association of the cytosolic protein p $^{\text {phox }}$. Apocynin has been used to prevent oxidative-stress-mediated cell damage in several disease models. Recently, apocynin has been proved to improve neurological function and can be used as a neuroprotective agent [64-68]. In the presence of microglial NADPH oxidase activation in vitro, apocynin was able to reduce extracellular ROS and cellular damage. Apocynin pretreatment $(0.5 \mathrm{mM}$ for $30 \mathrm{~min}$ ) also attenuated the rotenone-induced release of superoxides from activated microglia mediated by NADPH oxidase [55].

In another study, exposure to paraquat $(50 \mu \mathrm{M})$, a herbicide with a structure similar to the neurotoxin $\mathrm{MPP}^{+}$, has been shown to produce PD-like symptoms and generated ROS (including superoxide anions) in BV-2 cells. Paraquatinduced cytotoxicity in BV-2 cells was accompanied by translocation of the $\mathrm{p} 67^{\mathrm{phox}}$ cytosolic subunit of NADPH oxidase to the membrane. Paraquat-induced ROS production was significantly inhibited by apocynin (1 mM) [69]. Data from the studies above indicated that apocynin may inhibit the release of microglial NADPH-oxidase-mediated superoxide in microglia-enhanced degeneration of dopaminergic neurons.

Diphenyliodonium (DPI, Figure 1(d)) is a widely used selective NADPH oxidase inhibitor which was documented to act as a neuroprotective agent due to its potent anti-inflammatory properties mediated through the inhibition of ROS. At very low concentrations, DPI inhibited both extracellular superoxide and intracellular ROS production in dopaminergic neurons from LPS-induced degeneration and in LPS-treated microglial activation [70]. In a report by $\mathrm{Ma}$ and Zhou, DPI at 3-30 $\mu \mathrm{M}$ concentrations inhibited intrinsic NADPH oxidase activity in N27 cells. Furthermore, DPI blocked $\mathrm{MPP}^{+}$-induced ROS production. DPI also promoted the survival of primary striatal neurons [71] and protected against glutamate-induced apoptosis in dopaminergic SHSY5Y cells [72]. In addition, several in vivo studies demonstrated that DPI delivered protection against global cerebral ischemia [64], rotenone- [55], paraquat- [73], 6-OHDA[74], MPTP- [59], and IFN- $\gamma /$ LPS- [75] induced dopaminergic degeneration. In a recent study, Gao et al. [76] developed a two-hit (neuroinflammation and mutant $\alpha$-synuclein $(\alpha-$ syn) overexpression) animal model to investigate mechanisms through which mutant $\alpha$-syn and inflammation work in concert to mediate chronic PD neurodegeneration. Results revealed that LPS stimulation within the brain to transgenic mice over expressing human A53T mutant $\alpha$-syn developed persistent neuroinflammation, chronic progressive degeneration of the nigrostriatal dopamine pathway, accumulation of aggregated, nitrated $\alpha$-syn, and formation of Lewy bodylike inclusions in nigral neurons. Continuous inhibition of NADPH oxidase by 4 -week infusion of DPI $(5 \mu \mathrm{g} / \mathrm{kg} / \mathrm{h})$ blocked $\alpha$-syn pathology and nigral neurodegeneration. These studies provide a potential role of DPI in the treatment of PD.

Dextromethorphan (DM, Figure 1(e)) is neuroprotective through inhibition of microglial activation and NADPH oxidase activation. Earlier reports reveal that DM protects dopaminergic neurons against inflammation-mediated degeneration induced by LPS, through inhibition of superoxide radicals [77]. Furthermore, Li et al. [78] reported that femto$\left(10^{-13}\right.$ and $\left.10^{-14} \mathrm{M}\right)$ and micromolar $\left(10^{-5}\right.$ to $\left.10^{-7} \mathrm{M}\right)$ concentrations of DM (both pre- and posttreatment) showed equal efficacy in protecting LPS-induced dopaminergic neuron death in midbrain neuron-glia cultures. These studies indicated that the neuroprotective effect elicited by femtomolar concentrations of DM is mediated through 
the inhibition of LPS-induced proinflammatory mediators, especially superoxide. In another study, DM was reported to elicit neuroprotective effects in the MPTP-intoxicated PD model in mice. DM significantly reduced the MPTP-induced production of both extracellular superoxide free radicals and intracellular ROS in both in vitro and in vivo experiments [79].

Recently, Ramanathan et al. [80] revealed that DM increased superoxide dismutase (SOD) and catalase, reduced thiobarbituric acid reactive substances in the hippocampal and striatal regions of monosodium glutamate-induced neurodegeneration in rats, and improved neuroprotection based on its antioxidant properties. Another recent report also indicated that increased ROS production in activated BV-2 microglial cells by LPS was associated with increased expression of NADPH oxidase (NOX)-2, a subunit component of NADPH oxidase and DM significantly suppressed the upregulation of NOX-2 as well as subsequent ROS production in activated BV-2 cells [81]. In light of this, DM may form the potential therapeutic strategy for the treatment of PD. The metabolite of DM, 3-hydroxymorphinan (Figure 2(a)), also protected the nigrostriatal pathway against MPTP-elicited damage both in vivo and in vitro by reducing MPTP-elicited reactive microgliosis as evidenced by the decreased production of ROS due to its potent neuroprotection in PD [82].

Resveratrol (3, 4, 5-trihydroxy-trans-stilbene, Figure 2(b)), a nonflavonoid polyphenol naturally found in red wine and grapes, has been found to possess antioxidant, anticancer, and anti-inflammatory properties. Recent results from Zhang et al. [83] clearly demonstrated that resveratrol pretreatment $(15-60 \mu \mathrm{M})$ for $30 \mathrm{~min}$ stimulated with LPS $(10 \mathrm{ng} / \mathrm{mL})$ protected dopaminergic neurons against LPSinduced neurotoxicity in concentration and time-dependent manners through the inhibition of microglial activation and the subsequent reduction in release of proinflammatory factors. The authors showed that resveratrol reduced NADPHoxidase-mediated generation of ROS and inhibited the LPSinduced translocation of NADPH oxidase cytosolic subunit $\mathrm{p} 47^{\text {phox }}$ to the cell membrane. The most important finding is that resveratrol failed to exhibit neuroprotection in cultures from NADPH-oxidase-deficient mice. This data indicates that NADPH oxidase may be a major player in resveratrolmediated neuroprotection in the models of PD.

The epigallocatechin (EGCG, Figure 2(c)), a catechin polyphenol, was reported to reduce neuronal NADPH expression in rats exposed to acute hypoxia [84]. EGCG was also reported to inhibit cytosolic subunits of NADPH oxidase from translocating into the membrane, suggesting that inhibition of NADPH oxidase activity may prevent oxidative stress. In a recent report, the effects of EGCG on dichlorodiphenyltrichloroethane (DDT), a pesticide which is believed to play a causative role in the etiology of PD, was studied. It was found that EGCG concentration dependently $(1 \mu \mathrm{M}$, $3 \mu \mathrm{M}$, and $10 \mu \mathrm{M})$ reduced DDT-induced cell death in dopaminergic SH-SY5Y cells. Reports also indicated that EGCG was capable of reducing dopaminergic neurotoxin 6-hydroxydopamine-(6-OHDA-) induced cell death in SH-SY5Y cells [85] and MPTP-induced neurotoxicity in mice [86]. The<smiles>CCOC(=O)C(C)=O</smiles>

(a)<smiles>NCCc1ccc(S(=O)(=O)F)cc1</smiles>

(b)

(d)

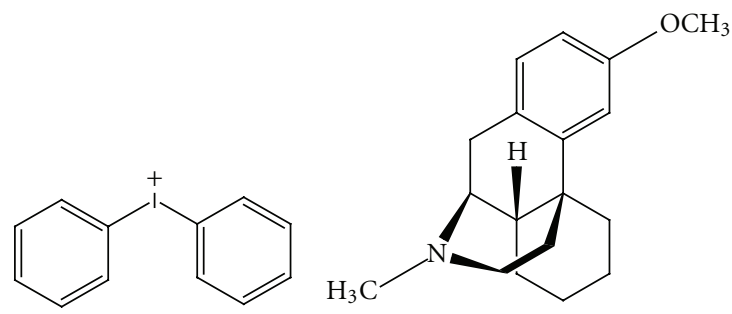<smiles>COc1cc(C(C)=O)ccc1O</smiles>

(c)

(e)
Figure 1: Chemical structure of ethyl pyruvate (a), aminoethylbenzenesulfonylfluoride (b), apocynin (c), diphenyliodonium (d) and dextromethorphan (e).

authors suggest that consumption of green tea, which contains high concentrations of EGCG, may provide potential prophylactic effects in reducing the risk of developing PD.

Few neuropeptides such as pituitary adenylate cyclaseactivating polypeptide (PACAP) 38, PACAP 27, and its internal peptide, Gly-Ile-Phe (GIF), were reported to be neuroprotective at $10^{-13} \mathrm{M}$ against LPS-induced dopaminergic neurotoxicity. PACAP is widely distributed in the peripheral and central nervous system, where PACAP release is reported to serve as a neuronal survival factor $[87,88]$. PACAP is reported to have diverse functions and has been shown to act as a neurotransmitter/neuromodulator [89] and a neuroprotectant [90, 91]. PACAP 38 and GIF also protected against MPTP-induced neurotoxicity in animal models. The polypeptides significantly ameliorated the production of microglia-derived ROS, where both LPS- and phorbol 12myristate 13-acetate-induced superoxide and intracellular ROS were inhibited. The study showed that PACAP38 and GIF were neuroprotective only in normal cultures and not in NADPH oxidase deficient cultures, proving the important role of NADPH oxidase for GIF and PACAP 38s neuroprotection [92].

The steroid hormone, $17 \beta$-estradiol (E2, Figure $2(\mathrm{~d})$ ), is released into the blood where it can exert trophic or regulatory effects on many different target tissues such as the breast, ovary, uterus, bone, and brain. Reports revealed that E2 treatment ( $0.025 \mathrm{mg}$; $14-21$ day release via minipumps) strongly attenuated the elevation of NADPH oxidase activity 
<smiles>O=C(CN1C2CCCC1c1cc(O)ccc1C2)c1ccccc1</smiles>

(a)

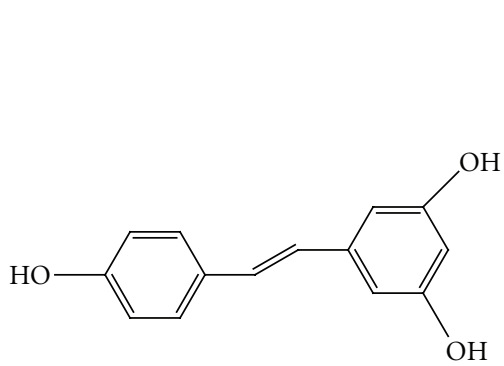

(b)<smiles>Oc1cc(O)c2c(c1)O[C@H](c1cc(O)c(O)c(O)c1)[C@H](O)C2</smiles>

(c)

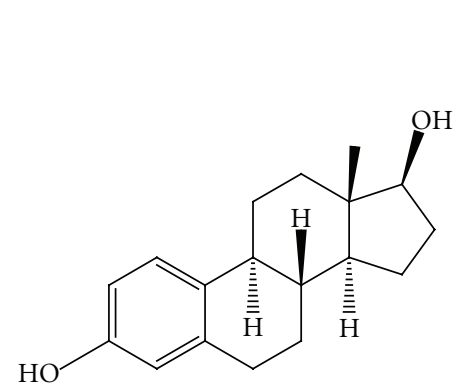

(d)

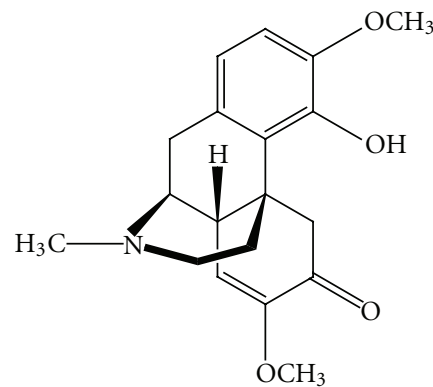

(e)

Figure 2: Chemical structure of 3-hydroxymorphinan (a), resveratrol (b), epigallocatechin (c), estradiol 17- $\beta$ (d), and sinomenine (e).

in the hippocampal CA1 region following cerebral ischemia in brain, which correlated with its suppression of $\mathrm{O}_{2}{ }^{-}$levels and its neuroprotective effect [93]. Moreover, E2 inhibited activation of the GTPase, Rac1, in an Akt-dependent manner following cerebral ischemia, which is critical for NOX-2 activation. Due to its neuroprotective effect and potent role in inhibiting NADPH oxidase expression, E2 may be further developed for the treatment of PD [94].

Transforming growth factor (TGF)- $\beta 1$ is a pleiotropic cytokine that plays a critical role in the control of cell growth, differentiation, inflammation, cell chemotaxis, apoptosis, and hematopoiesis. Studies have shown that TGF- $\beta 1$ can protect neurons from cell death induced by oxidative injury [95]. A recent report by Qian and Flood [96] revealed that the neuroprotective effects of TGF- $\beta 1$ are mainly attributed to its ability to inhibit the production of ROS from microglia during their activation or reactivation. TGF- $\beta 1$ inhibited LPSinduced NADPH oxidase subunit p $^{\text {phox }}$ translocation from the cytosol to the membrane in microglia, thereby exerting potent anti-inflammatory and neuroprotective properties.

Sinomenine (Figure 2(e)), a natural dextrorotatory morphinan analog, was reported to possess anti-inflammatory and neuroprotective properties by the inhibition of microglial NADPH oxidase. Sinomenine pretreatment for $30 \mathrm{~min}$ at micromolar $\left(10^{-6}-10^{-5} \mathrm{M}\right)$ and subpicomolar concentrations $\left(10^{-14}-10^{-13} \mathrm{M}\right)$ showed equivalent efficacy in protecting against dopaminergic neuron death in rat midbrain neuron-glial cultures. Furthermore, sinomenine suppressed LPS-induced extracellular ROS production via the inhibition of NADPH cytosolic subunit p $^{\text {phox }}$ translocation to the cell membrane. These findings strongly suggest that the protective effects of sinomenine are most likely mediated through the inhibition of microglial NADPH oxidase activity [70].

$\mathrm{N}$-[2-(4-hydroxy-phenyl)-ethyl]-2-(2,5-dimethoxy-phenyl)-3-(3-methoxy-4-hydroxy-phenyl)-acrylamide (FLZ, Figure 3(a)) is a squamosamide derivative reported to mediate anti-inflammatory and neuroprotective effects in both LPS and MPTP-intoxicated models of PD [97]. For in vivo studies, FLZ (75 mg/kg, p.o.) was administered $30 \mathrm{~min}$ before every MPTP injection $(15 \mathrm{mg} / \mathrm{kg}$, s.c.) for 6 consecutive days. For LPS $(2 \mathrm{ng} / \mathrm{mL})$ stimulation, $10 \mu \mathrm{M}$ of FLZ was pretreated for $1 \mathrm{~h}$. The neuroprotective effect of FLZ was attributed to a reduction in LPS-induced microglial production of proinflammatory factors such as superoxide, tumor necrosis factor- $\alpha$ (TNF- $\alpha$ ), nitric oxide (NO), and prostaglandin E2 $\left(\mathrm{PGE}_{2}\right)$. Findings from this study revealed that the anti-inflammatory properties of FLZ were mediated through inhibition of NADPH oxidase, the key microglial superoxide-producing enzyme [97].

Phycocyanobilin (PCB, Figure 3(b)), a chromophore derived from biliverdin, plays an essential light-harvesting role in many blue-green algae and cyanobacteria. It constitutes up to $1 \%$ of the dry weight of spirulina. Recently, it was reported that C-phycocyanin administered orally (the spirulina holoprotein that includes $\mathrm{PCB}$ ) suppresses the neurotoxic impact of the excitotoxin kainite in rats, and a diet high in spirulina ameliorates the loss of dopaminergic neurons in the MPTP-induced Parkinsonian syndrome in mice. The central physiological effects of PCB may also reflect inhibition of neuronal NADPH oxidase, which is known to have a modulatory impact on neuron function, and can mediate neurotoxicity in certain neurodegenerative diseases [98]. PCB has been shown to be a potent inhibitor of NADPH 


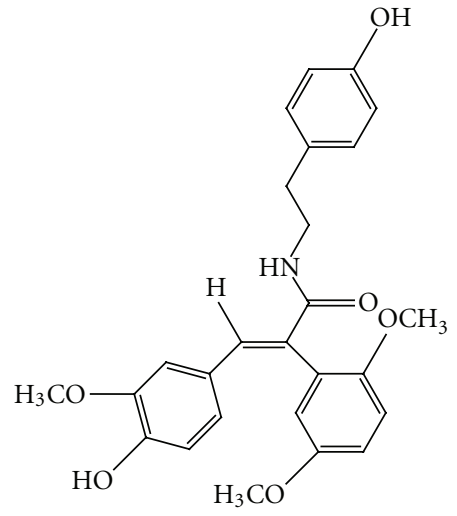

(a)

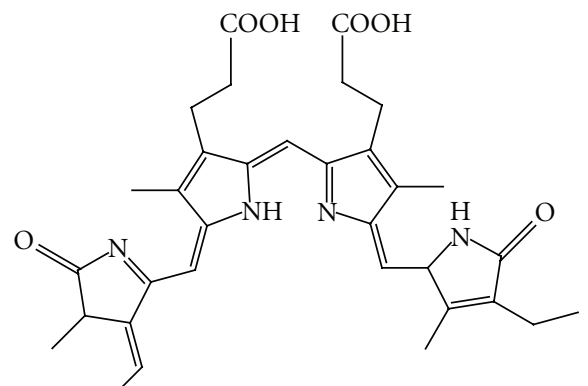

(b)

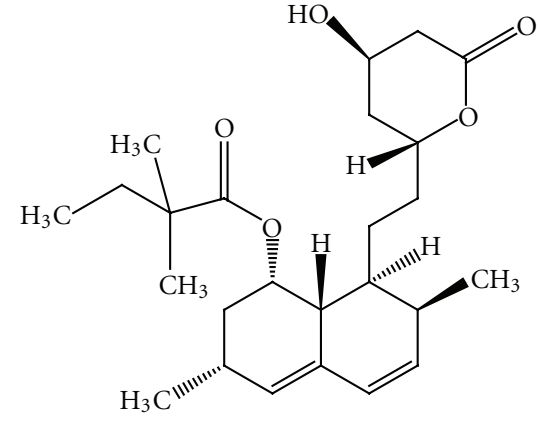

(c)<smiles>[2H][C@]12Cc3c(N(C)C)ccc(O)c3C(O)=C1C(=O)[C@]1(O)C(=O)/C(=C(\N)O)C(=O)[C@H](N(C)C)[C@]1([2H])C2</smiles>

(d)

FIGURE 3: Chemical structure of FLZ (a), phycocyanobilin (b), simvastatin (c), and minocycline (d).

oxidase activity in various human cell cultures at micromolar concentrations. PCB may thus have versatile potential for preserving the healthy function of the CNS in advanced old age patients suffering from neuroinflammatory diseases including PD.

In a recent study, Santiago et al. [99] investigated the effect of simvastatin (Figure 3(c)) a commonly used, cholesterol-lowering drug, in LPS and MPTP neurodegenerative models to identify its neuroprotective effects for PD. The study suggested that simvastatin $(5 \mathrm{mg} / \mathrm{kg}$ body weight, i.p.) could prevent neurotoxic damage by LPS stimulation in microglial cells. Studies by Brenneman et al. [90] also indicated that simvastatin is associated with a reduced incidence of dementia and PD in elderly patients. Simvastatin treatment $(10 \mu \mathrm{M})$ blocked the rac1-dependent activation of NADPH oxidase and $\mathrm{O}_{2}{ }^{-}$production and significantly diminished microglial CC chemokine ligand 5 (a major chemo attractant of inflammatory cells) expression induced by interferon- $\beta$ alone or by a combination of interferon- $\beta /$ TNF- $\alpha$, thereby exerting its suppressive effects on inflammation in the CNS [100]. Furthermore, simvastatin inhibited NADPH oxidase and the production of ROS in microglia [101]. A recent study showed that simvastatin protects dopaminergic neurodegeneration in in vivo parkinsonian models [102]. Further, simvastatin was also reported to attenuate superoxide generation by NADPH oxidase activation, protecting the endothelial cell barrier [103]. All these data suggest the protective effect of simvastatin against the degeneration of dopaminergic neurons and may be developed as a promising drug to provide neuroprotection in $\mathrm{PD}$.

Minocycline (Figure 3(d)), a well-known semisynthetic tetracycline derivative, is neuroprotective in several animal models of neurodegeneration, including PD [104, 105]. Studies have demonstrated that the neuroprotective actions of minocycline are attributable to inhibition of microglial activation accompanied by oxidative stress. Choi et al. [106] reported that minocycline $(25$ or $50 \mathrm{mg} / \mathrm{kg}$ ) exerted neuroprotection by significantly attenuating thrombin-induced neurotoxic effects through inhibition of NADPH oxidase activation and ROS production from activated microglia.

Several patents for various categories of compounds have been claimed for selectively inhibiting NADPH oxidase by proving to be useful in the treatment and/or prevention of inflammatory conditions in neurodegenerative diseases. Patented compounds published over the last five years for selectively inhibiting NADPH oxidase were collectively described in our earlier review [107]. The most recent relevant patents showing a possible role in ameliorating neurodegenerative diseases such as PD include the pyrazolo pyridine derivatives [108], tetrahydroindole derivatives [109], imipramine blue analogs [110], quinolone derivatives [111], and hesperidin and hesperetin analogs [112]. These compounds were shown to selectively inhibit and downregulate the expression of NADPH oxidase by suppressing ROS generation, consequently proving their importance as novel therapies in ameliorating neuroinflammatory degenerative diseases including PD. 
<smiles>CC(=N)NCCSCC[C@H](N)C(=O)O</smiles>

(a)<smiles>CC(=N)NCCCC[C@H](N)C(=O)O</smiles>

(b)<smiles>N=C(N)NN</smiles>

(c)<smiles>O=c1c(O)c(-c2ccc(O)c(O)c2)oc2cc(O)cc(O)c12</smiles>

(d)

Figure 4: Chemical structure of GW274150 (a), L-NIL (b), aminoguanidine (c), and quercetin (d).

\section{Role of iNOS-Derived ROS Signaling in PD}

Apart from the above-discussed NADPH-oxidase-derived ROS systems, focus also points to nitrogen dioxide-derived reactive species such as $\mathrm{ONOO}^{-}, \mathrm{NO}$, and other unrecognized potential reactive nitrogen species as the main culprits [113]. Due to their highly unstable nature and reactivity, biological molecules such as proteins, DNA, and lipids in dopaminergic neurons in the brains of parkinsonian patients could be targeted for oxidation resulting in extensive cellular injury and cell death. Normally, inducible NO synthase (iNOS) is not expressed in the brain, but in pathological situations, especially those associated with gliosis, iNOS can be induced.

In experimental PD models and MPTP neurotoxininduced models, induction of iNOS expression has been observed $[14,114]$. Earlier studies have also suggested that inhibition of iNOS showed neuroprotection in the MPTP-induced PD model. In addition, inflammatory mediators such as LPS and cytokines also cause an increase in iNOS expression in microglia and astrocytes [115] and possibly in neurons [116]. Once expressed, iNOS produces high levels of NO continuously from microglia or astrocytes [117, 118].

Nitric oxide, a lipophilic diatomic molecule, can travel several micrometers away from its site of production and freely cross the plasma membrane to reach the intracellular space of dopaminergic neurons. Also, the interaction of $\mathrm{NO}$ and $\mathrm{O}_{2}{ }^{-}$will result in the formation of $\mathrm{OONO}^{-}$, a highly reactive species. Peroxynitrite is a potent cytotoxic oxidant, which in turn will inflict oxidative damage to biological targets such as inactivating ion channels, damaging DNA, and nitrating tyrosine residues that can potentially inactivate enzymes and disrupt signal transduction [119]. Therefore, inhibition of glial activation-mediated oxidative stress by reducing the iNOS may have therapeutic value in the treatment of neuroinflammation related to PD. In the following section, we describe recently available agents and patented compounds that selectively inhibit iNOS activity and may show a promising role in PD treatment.

\section{Inducible Nitric Oxide Synthase Inhibitors and Experimental Models of PD}

It is well documented that experimental PD models using various toxins and MPTP-induced dopaminergic degeneration express high levels of iNOS $[37,120]$. Recently, Broom et al. [121] reported a selective iNOS inhibitor, GW274150 ([2[(1-iminoethyl) amino] ethyl]-L-homocysteine, Figure 4(a)) showing a potent role in the pathogenesis of PD. They indicated that 6-OHDA administration produced an increased number of cells expressing iNOS and was also associated with increased microglial activation. GW274150 treatment $(3,10$, and $30 \mathrm{mg} / \mathrm{kg})$ orally twice daily for 7 consecutive days leads to a suppression of iNOS expression and the inflammatory response in the 6-OHDA model of PD and was neuroprotective but at a narrow therapeutic range. The findings from this paper support the concept that NO has a detrimental effect on dopaminergic neurons and that modulation of the inflammatory response may be a valid neuroprotective therapeutic approach in treating PD.

Gahm et al. [122] reported that L-N-iminoethyl-lysine (L-NIL, Figure 4(b)), a selective iNOS inhibitor, appeared to protect the injured brain by limiting $\mathrm{OONO}^{-}$formation. Their study analyzed a variety of parameters including neuronal degeneration, survival, cellular apoptosis, and formation of nitrotyrosine following traumatic brain injury (TBI). L-NIL significantly reduced iNOS activity in animals injured by brain contusion. Moreover, neuronal degeneration and NT immunoreactivity significantly reduced at $24 \mathrm{~h}$. Neuronal survival was unchanged at $24 \mathrm{~h}$ but increased at 6 days in L-NIL-treated animals. Cellular apoptosis of mononuclear phagocytes (ED-1) and neuron (NeuN) positive cells were significantly reduced following L-NIL treatment 6 days after 
<smiles>COc1cc(CNC(=O)CC(C)(C)C)ccc1CC(O)CO</smiles>

(a)<smiles>NCCCCN=C(N)N</smiles>

(b)<smiles>COc1c(O)cc(O)c2c(=O)cc(-c3ccccc3)oc12</smiles>

(c)

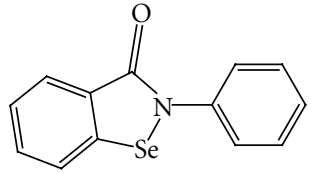

(d)

FIGURE 5: Chemical structure of glyceryl nonivamide (a), agmatine (b), wogonin (c), and ebselen (d).

trauma. These findings also strongly support a putative harmful role of iNOS induction early after TBI and the neuroprotective role of L-NIL in neurodegenerative diseases such as PD.

The neuroprotective actions of aminoguanidine (AG, Figure 4(c)) have long been studied. Several authors reported that the selective inhibition of iNOS is one of the major mechanisms by which AG exerts its neuroprotection [123125]. Cash et al. [126] reported the neuroprotective effects of AG on transient focal ischemia in the rat brain. Lu et al. [127] proposed the neuroprotective action of AG by combined magnetic resonance imaging and histopathologic and functional analysis after lateral fluid-percussive brain injury in rats. The cerebroprotective effect of AG in a rodent model of stroke was also studied [128]. In a recent report [129], the effectiveness of AG was studied in modulating the toxicity of aluminum chloride on the nitrite levels, malondialdehyde concentration, reduced glutathione content, and cytochrome c oxidase activity in Wistar rats and confirmed that the inhibition of iNOS was responsible for this action. All these studies have concluded that the potent inhibition of iNOS activity was partly responsible for neuroprotection and AG can be further developed in the prevention of various CNS disorders including PD.

Quercetin (Figure 4(d)), a major flavonoid naturally occurring in plants, deserves attention because of its beneficial effects observed in various in vitro and in vivo neural damage models. Quercetin significantly exerted a neuroprotective effect through inhibition of the iNOS/NO system and proinflammation gene expression in PC12 cells and in Zebrafish [130]. The selective dopaminergic neurotoxin 6OHDA was used to induce neural damage in PC12 cells and Zebrafish. Pretreatment with quercetin offered neuroprotection against 6-OHDA-induced PC12 apoptotic cell death and dopaminergic neuronal loss in Zebrafish. A mechanistic study revealed that quercetin could inhibit NO overproduction and iNOS overexpression in PC12 cells and downregulates the overexpression of proinflammatory genes suggesting that role of quercetin in neuroprotection leading to its development as an effective therapeutic agent for the treatment neurodegenerative diseases including PD.

The neuroprotective effects of glyceryl nonivamide (GLNVA, Figure 5(a)), a vanilloid receptor (VR) agonist on activated microglia and 6-OHDA-induced neurotoxicity in dopaminergic SH-SY5Y cells were studied recently [131]. The authors revealed that GLNVA decreased LPS-activated microglia-induced overexpression of neuronal nitric-oxide synthase and gp91 $1^{\text {phox }}$ on SH-SY5Y cells. GLNVA $(1,10$, $100 \mu \mathrm{M})$ for $24 \mathrm{~h}$ diminished LPS-induced NO production, overexpression of iNOS, and intracellular reactive oxygen species in activated microglia. 6-OHDA-induced overexpression of nNOS, iNOS, COX-2, and gp91 ${ }^{\text {phox }}$ were also reduced by GLNVA in SH-SY5Y cells. The neuroprotective effects of GLNVA are mediated, at least in part, by decreasing the inflammation- and oxidative-stress-associated factors induced by microglia and 6-OHDA.

The neuroprotective effects of exogenous agmatine, a guanidinium compound (Figure 5(b)), were investigated in experimental spinal cord injury (SCI). Agmatine is a neurotransmitter-neuromodulator with both $N$-methyl-D-aspartate receptor (NMDAR) - antagonizing and NO synthaseinhibiting activities. Agmatine administration following SCI was shown to reduce NO levels significantly and suggested that this drug may be helpful in the treatment of patients with neurodegeneration especially in SCIs [132]. In a recent study, the effects of agmatine on cell injury induced by rotenone commonly used in establishing in vivo and in vitro models of PD in a human-derived dopaminergic SH-SY5Y cell line were shown. Agmatine dose-dependently suppressed rotenone-induced cellular injury through a reduction of oxidative stress, by protecting dopaminergic neurons [133].

Wogonin (5, 7-dihydroxy-8-methoxyflavone, Figure 5(c)), an active component originated from the root of Scutellaria baicalensis, has been reported to possess antioxidant and anti-inflammatory properties. Wogonin $(5,20$, $50 \mathrm{mM}$ ) inhibited inflammatory activation of cultured brain 


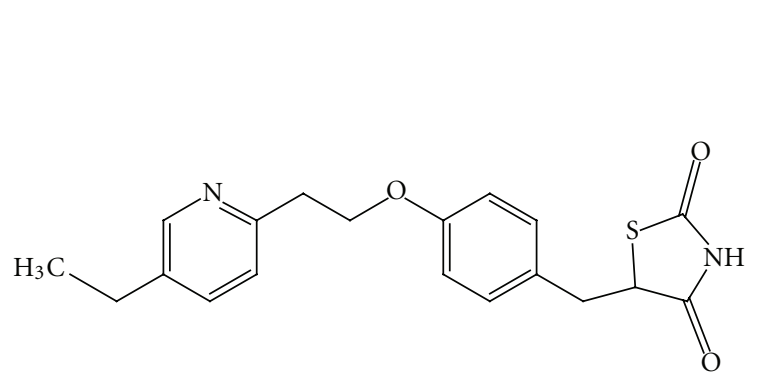

(a)<smiles>Fc1ccc([C@H]2CCNC[C@H]2COc2ccc3c(c2)OCO3)cc1</smiles>

(b)<smiles>[R1]c1cc2nc(I=C3CCCCC(N)=N3)[nH]c2c(Br)c1Br</smiles>

(c)<smiles>[R][X]c1c([X])c(=O)oc2c([Y4])c([X])c([Y4])c([Y4])c12</smiles>

(d)

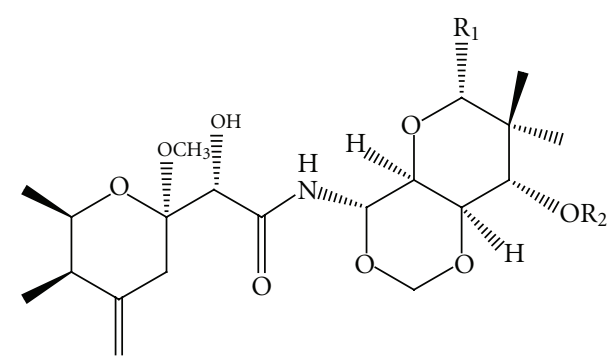

(e)

FIGURE 6: Chemical structure of pioglitazone (a), paroxetine (b), imidazopyridine (c), coumarins (d), and theopederin derivatives (e).

microglia by diminishing LPS-induced NO production via suppressing iNOS induction in microglia [134]. Furthermore, Chun et al. [135] reported the inhibitory activities of wogonin derivatives on LPS-induced $\mathrm{NO}$ production in $\mathrm{BV}-2$ microglial cells and on $\mathrm{H}_{2} \mathrm{O}_{2}$-induced neuronal cell death in SH-SY5Y cells. Wogonin and its derivatives ranging between $5,10,20$, and $40 \mu \mathrm{M}$ concentration decreased the production of $\mathrm{NO}$ and inflammatory cytokines owing to their potential role in mitigating neuroinflammation seen in $\mathrm{PD}$.

2-Phenyl-1,2-benzisoselenazole-3(2H)-one (ebselen), a seleno organic compound and a strong $\mathrm{ONOO}^{-}$cleansing agent (Figure 5(d)), possesses antioxidant and anti-inflammatory properties and is now under clinical trials for the treatment of ischemic stroke. Earlier reports indicated that ebselen can also preferentially inhibit the activity of inducible nitric oxide (NO) synthase within a certain concentration range [136]. Ebselen prevented both neuronal loss and clinical symptoms in a primate MPTP model of PD. Ebselen $(10 \mu \mathrm{M})$ also prevented peroxide radical overproduction induced by serum withdrawal in cultured PC12 cells and hydroxyl radical generation induced by the mitochondrial toxin, $\mathrm{MPP}^{+}$, in an in vivo system in the rat brain [137]. The authors indicated that ebselen inhibited the free radical production and may be useful as preventive treatment in PD.

Pioglitazone, a PPARgamma agonist (Figure 6(a)), was reported to protect mice from MPTP-induced dopaminergic cell loss, glial activation, and loss of catecholamines in the striatum. In addition, pioglitazone $(10 \mu \mathrm{M})$ provided neuroprotective properties to substantia nigra dopaminergic neurons in LPS-induced PD models both in vivo and in vitro $[138,139]$. In mice treated with pioglitazone, there was reduced activation of microglia, reduced induction of iNOS-positive cells and less glial fibrillary acidic protein positive cells in both the striatum and substantia nigra pars compacta. A comprehensive mechanistic study revealed that pioglitazone-mediated neuroprotection involves inhibition of microglial activation and decreased expression and activity of iNOS and may offer a treatment opportunity in PD to slow the progression of disease that is mediated by neuroinflammation $[138,140]$.

Recently, the antidepressant paroxetine (Figure 6(b)) was reported to promote the survival of nigrostriatal dopaminergic neurons in the MPTP mouse model of PD. Treatment with paroxetine $(10 \mathrm{mg} / \mathrm{kg}$ body weight, equivalent to $0.2-$ $0.25 \mathrm{mg}$ /day) into the peritoneum for 6 days, beginning at $12 \mathrm{~h}$ after last MPTP injection, prevented the degeneration of nigrostriatal DA neurons, increased striatal dopamine levels, and improved motor function. The authors indicated that the neuroprotection afforded by paroxetine may partly be associated with the suppression of iNOS in activated microglia [141].

During the last five years, several novel compounds that selectively inhibit iNOS expression have been patented. Thomas et al. [142] claimed the usefulness of imidazopyridine derivatives (Figure 6(c)) as iNOS inhibitors. They found the novel 7-amino-3, 4, 5, 6, tetrahydro-2H-azepin-2-ylsubstituted imidazopyridine derivatives have valuable pharmacological properties which make them commercially utilizable. They are selective inhibitors of the enzyme iNOS. On account of their iNOS-inhibiting properties, the compounds according to the invention can be employed in human, veterinary medicine, and therapeutics, where an excess of NO or $\mathrm{O}_{2}{ }^{-}$is involved due to iNOS activation. They can be used without limitation for the treatment and prophylaxis of various neuroinflammatory and neurodegenerative diseases including PD [142]. 


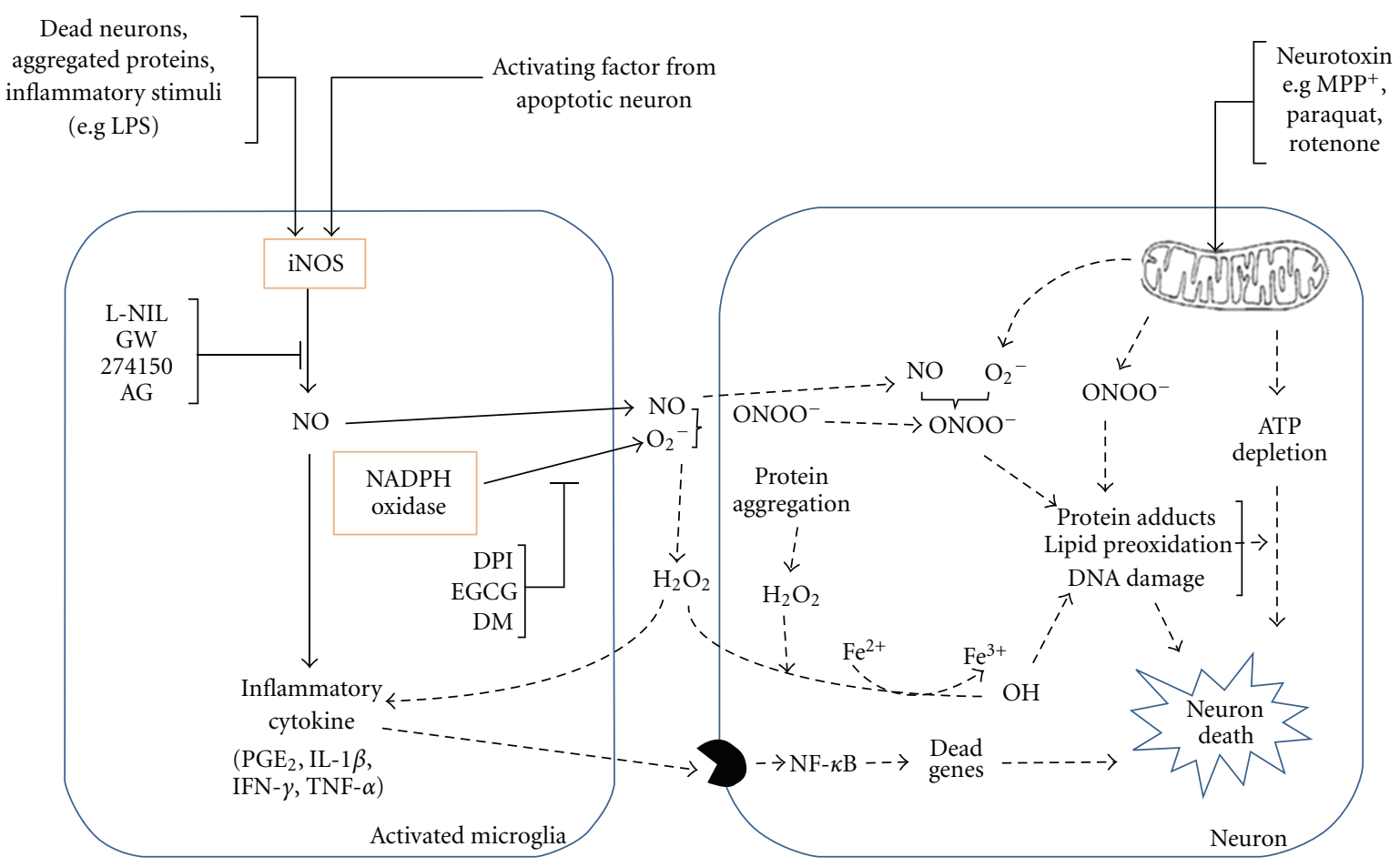

FIGURE 7: Role of iNOS and NADPH oxidase and their inhibitors in oxidative stress and neuronal damage. Reactive oxygen species (ROS) can be generated in distinct ways, for example, cell activation by neurotoxins (MPTP, paraquat, and rotenone), and mitochondrial dysfunction and protein aggregation. ROSs have a role in oxidative stress, thereby causing neuronal injury or cell death which can be a factor for microglial activation. Several inhibitors of iNOS (L-N-iminoethyl-lysine (L-NIL), GW 274150, and aminoguanidine (AG)) and NADPH oxidase inhibitors diphenyliodonium (DPI), epigallocatechin (EGCG), and dextromethorphan (DM) as shown inhibit the generation of nitric oxide and superoxides, thereby inhibiting the formation of ROS and preventing neurodegeneration. Abbreviations: iNOS: inducible nitric oxide synthase, LPS: lipopolysaccharides, NADPH oxidase: nicotinamide adenine dinucleotide phosphate-oxidase, $\mathrm{NO}$ : nitric oxide, $\mathrm{O}_{2}{ }^{-}$: peroxy radical, $\mathrm{ONOO}^{-}$: peroxynitrite, NF- $\kappa \mathrm{B}$ : nuclear factor kappa, $\mathrm{H}_{2} \mathrm{O}_{2}$ : hydrogen peroxide, TNF- $\alpha$ : tumor necrosis factor-alpha, PGE 2 : prostaglandin E2, IL-1 $\beta$ : interleukin-1 beta, and IFN- $\gamma$ : interferon-gamma.

A patent has also been obtained by Sharon et al. [143] on a few novel coumarins (Figure 6(d)) for their use as inhibitors of iNOS. Their study reveals that the compounds synthesized from their invention can be used for various neurodegenerative diseases including PD.

Recently, Tadayoshi et al. [144] filed a patent for a sense oligonucleotide with sequence complementary to a singlestranded RNA (antisense transcript) with sequence complementary to mRNA of the iNOS gene in order to control expression of iNOS. The authors reveal that the proposed invention can control the expression of iNOS and can be useful for biological defense in ameliorating diseases related to excessive production of $\mathrm{NO}$, such as neuroinflammation.

Theopederin and derivatives (Figure 6(e)) are marine natural substances isolated and purified from Porifera species. In a recent patent, a pharmaceutical and health food preparation containing theopederin derivatives as active constituents was claimed by Heonjoong and Hyun-Sil [145]. The authors claim that these derivatives selectively inhibit the excessive generation of $\mathrm{NO}$ and iNOS activation and are useful to treat and/or prevent various diseases including autoimmune diseases, inflammatory diseases, multiple sclerosis, and neurodegeneration.

There has also been a patent filed by Singh [146] on the exemplary compound lovastatin, which is a sodium salt of phenylacetic acid, FPT inhibitor II, N-acetyl cysteine, and cyclic AMP, selectively inhibit the iNOS activation in LPSstimulated microglial cells, and can be used for the treatment of various neuroinflammatory diseases.

The role of iNOS and NADPH oxidase in oxidative stress and neuronal damage and the potential therapeutic strategy of the discussed compounds were represented in Figure 7. In view of the published reports and patents filed, inhibition of iNOS and NADPH oxidase by various existing and emerging molecules would be one of the ideal targets for the treatment for PD.

\section{Conclusion}

The etiology of PD remains unknown, and the mechanisms controlling the selective and progressive degeneration of the nigrostriatal dopaminergic pathway are poorly understood. Therapeutic intervention aimed at halting the degenerative nature observed in PD is of prime importance and presents some research opportunities. Studies of postmortem PD brains and various cellular and animal models of PD in the last two decades strongly suggest that the neuroinflammation caused by oxidative stress is one of the major mechanisms in PD pathology. It is believed that activated glial cells, which 
comprise the majority of this inflammatory response, contribute to neurodegeneration through the production of ROS. Currently, ROS-generating oxidative enzymes are emerging as major therapeutic targets to inhibit neurotoxicity seen in PD.

A range of data during the past few years suggest that anti-inflammatory agents with neuroprotective effects by inhibiting inflammatory oxidative enzymes in experimental models may be capable of preventing or reducing neuronal degeneration and arrest the progression of PD. Although several anti-inflammatory agents were known to inhibit the ROS, none has been specific and the results achieved are somewhat inconsistent and show limited mechanistic relevance to PD. Thus, inhibitors of major ROS-generating NADPH oxidase and iNOS that have a decent proven record of safety and efficacy would be promising candidates. The compounds discussed in this paper provide valuable information in selectively inhibiting the ROS generated by oxidative enzymes in in vitro and in vivo experimental models of PD. These compounds must be proved for their safety, selectivity, toxicity, bioavailability, therapeutic window, and absence of significant side effects. Furthermore, combination therapy of selected agents in the correct time frame and dose may also provide better results to achieve synergistic clinical effects.

However, a complete understanding of the molecular mechanisms of the specificities of ROS in PD, and larger studies both epidemiologic and randomized clinical trials in humans, as well as animal studies, are needed to validate these findings in delivering beneficial effects in the treatment of PD.

\section{Acknowledgments}

This work was financially supported by the Ministry of Education, Science Technology (MEST) and Korea Industrial Technology Foundation (KOTEF) through the Human Resource Training Project for Regional Innovation and also supported by Basic Science Research Program through the National Research Foundation of Korea(NRF) funded by the Ministry of Education, Science and Technology (20110014923).

\section{References}

[1] A. Reynolds, C. Laurie, R. Lee Mosley, and H. E. Gendelman, "Oxidative stress and the pathogenesis of neurodegenerative disorders," International Review of Neurobiology, vol. 82, pp. 297-325, 2007.

[2] A. Nunomura, G. Perry, M. A. Pappolla et al., "RNA oxidation is a prominent feature of vulnerable neurons in Alzheimer's disease," Journal of Neuroscience, vol. 19, no. 6, pp. 1959-1964, 1999.

[3] K. J. Barnham, C. L. Masters, and A. I. Bush, "Neurodegenerative diseases and oxidatives stress," Nature Reviews Drug Discovery, vol. 3, no. 3, pp. 205-214, 2004.

[4] J. Emerit, M. Edeas, and F. Bricaire, "Neurodegenerative diseases and oxidative stress," Biomedicine and Pharmacotherapy, vol. 58, no. 1, pp. 39-46, 2004.
[5] M. Inoue, E. F. Sato, M. Nishikawa et al., "Mitochondrial generation of reactive oxygen species and its role in aerobic life," Current Medicinal Chemistry, vol. 10, no. 23, pp. 24952505, 2003.

[6] B. M. Babior, "NADPH oxidase," Current Opinion in Immunology, vol. 16, no. 1, pp. 42-47, 2004.

[7] K. K. Griendling, D. Sorescu, and M. Ushio-Fukai, "NAD(P) $\mathrm{H}$ oxidase: role in cardiovascular biology and disease," Circulation Research, vol. 86, no. 5, pp. 494-501, 2000.

[8] G. Groeger, C. Quiney, and T. G. Cotter, "Hydrogen peroxide as a cell-survival signaling molecule," Antioxidants and Redox Signaling, vol. 11, no. 11, pp. 2655-2671, 2009.

[9] M. Valko, D. Leibfritz, J. Moncol, M. T. D. Cronin, M. Mazur, and J. Telser, "Free radicals and antioxidants in normal physiological functions and human disease," International Journal of Biochemistry and Cell Biology, vol. 39, no. 1, pp. 44-84, 2007.

[10] H. Pelicano, D. Carney, and P. Huang, "ROS stress in cancer cells and therapeutic implications," Drug Resistance Updates, vol. 7, no. 2, pp. 97-110, 2004.

[11] C. E. Thomas and B. Kalyanaraman, Oxygen Radicals and the Disease Process, Hardwood Academic Publishers, 1997.

[12] B. Halliwell and J. M. C. Gutteridge, "Role of free radicals and catalytic metal ions in human disease: an overview," Methods in Enzymology, vol. 186, pp. 1-85, 1990.

[13] D. C. Wu, P. Teismann, K. Tieu et al., "NADPH oxidase mediates oxidative stress in the 1-methyl-4-phenyl-1,2,3,6-tetrahydropyridine model of Parkinson's disease," Proceedings of the National Academy of Sciences of the United States of America, vol. 100, no. 10, pp. 6145-6150, 2003.

[14] G. T. Liberatore, V. Jackson-Lewis, S. Vukosavic et al., "Inducible nitric oxide synthase stimulates dopaminergic neurodegeneration in the MPTP model of Parkinson disease," Nature Medicine, vol. 5, no. 12, pp. 1403-1409, 1999.

[15] S. Hunot, F. Boissière, B. Faucheux et al., "Nitric oxide synthase and neuronal vulnerability in Parkinson's disease," Neuroscience, vol. 72, no. 2, pp. 355-363, 1996.

[16] S. Przedborski and H. Ischiropoulos, "Reactive oxygen and nitrogen species: weapons of neuronal destruction in models of Parkinson's disease," Antioxidants and Redox Signaling, vol. 7, no. 5-6, pp. 685-693, 2005.

[17] A. H. V. Schapira, "Pathogenesis of Parkinson's disease," Bailliere's Clinical Neurology, vol. 6, no. 1, pp. 15-36, 1997.

[18] Z. I. Alam, S. E. Daniel, A. J. Lees, D. C. Marsden, P. Jenner, and B. Halliwell, "A generalised increase in protein carbonyls in the brain in Parkinson's but not incidental Lewy body disease," Journal of Neurochemistry, vol. 69, no. 3, pp. 13261329, 1997.

[19] J. B. Schulz and M. F. Beal, "Mitochondrial dysfunction in movement disorders," Current Opinion in Neurology, vol. 7, no. 4, pp. 333-339, 1994.

[20] A. Slivka and G. Cohen, "Hydroxyl radical attack on dopamine," Journal of Biological Chemistry, vol. 260, no. 29, pp. 15466-15472, 1985.

[21] J. T. Greenamyre and T. G. Hastings, "Parkinsons—divergent causes convergent mechanisms," Science, vol. 304, no. 5674, pp. 1120-1122, 2004.

[22] H. Ischiropoulos and J. S. Beckman, "Oxidative stress and nitration in neurodegeneration: cause, effect, or association?" Journal of Clinical Investigation, vol. 111, no. 2, pp. 163-169, 2003.

[23] P. Jenner, "Oxidative stress in Parkinson's disease," Annals of Neurology, vol. 53, supplement 3, pp. S26-S38, 2003. 
[24] A. G. Kanthasamy, M. Kitazawa, A. Kanthasamy, and V. Anantharam, "Role of proteolytic activation of protein Kinase $\mathrm{C} \delta$ in oxidative stress-induced apoptosis," Antioxidants and Redox Signaling, vol. 5, no. 5, pp. 609-620, 2003.

[25] E. Koutsilieri, C. Scheller, E. Grünblatt, K. Nara, J. Li, and P. Riederer, "Free radicals in Parkinson's disease," Journal of Neurology, vol. 249, no. 2, supplement 2, pp. II1-II5, 2002.

[26] R. Love, "Mitochondria back in the spotlight in Parkinson's disease," Lancet Neurology, vol. 3, no. 6, p. 326, 2004.

[27] T. M. Tikka, N. E. Vartiainen, G. Goldsteins et al., "Minocycline prevents neurotoxicity induced by cerebrospinal fluid from patients with motor neurone disease," Brain, vol. 125, no. 4, pp. 722-731, 2002.

[28] J. K. Andersen, "Iron dysregulation and Parkinson's disease," Journal of Alzheimer's Disease, vol. 6, pp. S47-S52, 2004.

[29] C. Mancuso, G. Scapagnini, D. Currò et al., "Mitochondrial dysfunction, free radical generation and cellular stress response in neurodegenerative disorders," Frontiers in Bioscience, vol. 12, no. 3, pp. 1107-1123, 2007.

[30] S. Mandel, G. Maor, and M. B. H. Youdim, "Iron and $\alpha$-synuclein in the substantia nigra of MPTP-treated mice: effect of neuroprotective drugs R-apomorphine and green tea polyphenol (-)-epigallocatechin-3-gallate," Journal of Molecular Neuroscience, vol. 24, no. 3, pp. 401-416, 2004.

[31] M. B. H. Youdim, G. Stephenson, and D. B. Shachar, "Ironing iron out in Parkinson's disease and other neurodegenerative diseases with iron chelators: a lesson from 6-hydroxydopamine and iron chelators, desferal and VK-28," Annals of the New York Academy of Sciences, vol. 1012, pp. 306-325, 2004.

[32] J. L. Venero, M. A. Burguillos, P. Brundin, and B. Joseph, "The executioners sing a new song: killer caspases activate microglia," Cell Death and Differentiation, vol. 18, no. 11, pp. 1679-1691, 2011.

[33] D. W. Dickson, S. C. Lee, L. A. Mattiace, S. H. Yen, and C. Brosnan, "Microglia and cytokines in neurological disease, with special reference to AIDS and Alzheimer's disease," Glia, vol. 7, no. 1, pp. 75-83, 1993.

[34] P. L. McGeer, S. Itagaki, B. E. Boyes, and E. G. McGeer, "Reactive microglia are positive for HLA-DR in the substantia nigra of Parkinson's and Alzheimer's disease brains," Neurology, vol. 38, no. 8, pp. 1285-1291, 1988.

[35] C. S. Raine, "Multiple sclerosis: immune system molecule expression in the central nervous system," Journal of Neuropathology and Experimental Neurology, vol. 53, no. 4, pp. 328-337, 1994.

[36] J. Rogers, J. Luber-Narod, S. D. Styren, and W. H. Civin, "Expression of immune system-associated antigens by cells of the human central nervous system: relationship to the pathology of Alzheimer's disease," Neurobiology of Aging, vol. 9, no. 4, pp. 339-349, 1988.

[37] C. Knott, G. Stern, and G. P. Wilkin, "Inflammatory regulators in Parkinson's disease: iNOS, lipocortin-1, and cyclooxygenases-1 and -2," Molecular and Cellular Neuroscience, vol. 16, no. 6, pp. 724-739, 2000.

[38] D. K. Choi, S. Pennathur, C. Perier et al., "Ablation of the inflammatory enzyme myeloperoxidase mitigates features of Parkinson's disease in mice," Journal of Neuroscience, vol. 25, no. 28, pp. 6594-6600, 2005.

[39] K. Van Leyen, K. Arai, G. Jin et al., "Novel lipoxygenase inhibitors as neuroprotective reagents," Journal of Neuroscience Research, vol. 86, no. 4, pp. 904-909, 2008.
[40] C. K. Glass, K. Saijo, B. Winner, M. C. Marchetto, and F. H. Gage, "Mechanisms Underlying Inflammation in Neurodegeneration," Cell, vol. 140, no. 6, pp. 918-934, 2010.

[41] R. M. Ransohoff and V. H. Perry, "Microglial physiology: unique stimuli, specialized responses," Annual Review of Immunology, vol. 27, pp. 119-145, 2009.

[42] H. Chen, "Nonsteroidal antiinflammatory drugs and the risk of Parkinson's disease," Movement Disorder, vol. 17, pp. S143S144, 2002.

[43] P. L. McGeer and E. G. McGeer, "Inflammatory processes in amyotrophic lateral sclerosis," Muscle and Nerve, vol. 26, no. 4, pp. 459-470, 2002.

[44] B. M. Babior, "NADPH oxidase: an update," Blood, vol. 93, no. 5, pp. 1464-1476, 1999.

[45] M. Sawada, K. Imamura, and T. Nagatsu, "Role of cytokines in inflammatory process in Parkinson's disease," Journal of Neural Transmission, Supplement, no. 70, pp. 373-381, 2006.

[46] F. Serrano, N. S. Kolluri, F. B. Wientjes, J. P. Card, and E. Klann, "NADPH oxidase immunoreactivity in the mouse brain," Brain Research, vol. 988, no. 1-2, pp. 193-198, 2003.

[47] M. Ushio-Fukai, "Localizing NADPH oxidase-derived ROS," Science's STKE, vol. 2006, no. 349, p. re8, 2006.

[48] D. W. Infanger, R. V. Sharma, and R. L. Davisson, "NADPH oxidases of the brain: distribution, regulation, and function," Antioxidants and Redox Signaling, vol. 8, no. 9-10, pp. 15831596, 2006.

[49] B. J. Tabner, S. Turnbull, O. El-Agnaf, and D. Allsop, "Production of reactive oxygen species from aggregating proteins implicated in Alzheimer's disease, Parkinson's disease and other neurodegenerative diseases," Current Topics in Medicinal Chemistry, vol. 1, no. 6, pp. 507-517, 2001.

[50] W. Zhang, T. Wang, Z. Pei et al., "Aggregated $\alpha$-synuclein activates microglia: a process leading to disease progression in Parkinson's disease," FASEB Journal, vol. 19, no. 6, pp. 533542, 2005.

[51] M. P. Thomas, K. Chartrand, A. Reynolds, V. Vitvitsky, R. Banerjee, and H. E. Gendelman, "Ion channel blockade attenuates aggregated alpha synuclein induction of microglial reactive oxygen species: relevance for the pathogenesis of Parkinson's disease," Journal of Neurochemistry, vol. 100, no. 2, pp. 503-519, 2007.

[52] R. Tolando, A. Jovanović, R. Brigelius-Flohé, F. Ursini, and M. Maiorino, "Reactive oxygen species and proinflammatory cytokine signaling in endothelial cells: effect of selenium supplementation," Free Radical Biology and Medicine, vol. 28, no. 6, pp. 979-986, 2000.

[53] M. Sundaresan, Z. X. Yu, V. J. Ferrans, K. Irani, and T. Finkel, "Requirement for generation of $\mathrm{H}_{2} \mathrm{O}_{2}$ for plateletderived growth factor signal transduction," Science, vol. 270, no. 5234, pp. 296-299, 1995.

[54] K. Suzukawa, K. Miura, J. Mitsushita et al., "Nerve growth factor-induced neuronal differentiation requires generation of Rac1-regulated reactive oxygen species," Journal of Biological Chemistry, vol. 275, no. 18, pp. 13175-13178, 2000.

[55] H. M. Gao, B. Liu, and J. S. Hong, "Critical role for microglial NADPH oxidase in rotenone-induced degeneration of dopaminergic neurons," Journal of Neuroscience, vol. 23, no. 15, pp. 6181-6187, 2003.

[56] M. L. Block, X. Wu, Z. Pei et al., "Nanometer size diesel exhaust particles are selectively toxic to dopaminergic neurons: the role of microglia, phagocytosis, and NADPH oxidase," FASEB Journal, vol. 18, no. 13, pp. 1618-1620, 2004. 
[57] L. Qin, Y. Liu, C. Cooper, B. Liu, B. Wilson, and J. S. Hong, "Microglia enhance $\beta$-amyloid peptide-induced toxicity in cortical and mesencephalic neurons by producing reactive oxygen species," Journal of Neurochemistry, vol. 83, no. 4, pp. 973-983, 2002.

[58] X. F. Wu, M. L. Block, W. Zhang et al., "The role of microglia in paraquat-induced dopaminergic neurotoxicity," Antioxidants and Redox Signaling, vol. 7, no. 5-6, pp. 654-661, 2005.

[59] H. M. Gao, J. S. Hong, W. Zhang, and B. Liu, "Synergistic dopaminergic neurotoxicity of the pesticide rotenone and inflammogen lipopolysaccharide: relevance to the etiology of Parkinson's disease," Journal of Neuroscience, vol. 23, no. 4, pp. 1228-1236, 2003.

[60] S. P. Green, B. Cairns, J. Rae et al., "Induction of gp91-phox, a component of the phagocyte NADPH oxidase, in microglial cells during central nervous system inflammation," Journal of Cerebral Blood Flow and Metabolism, vol. 21, no. 4, pp. 374384, 2001.

[61] V. Anantharam, S. Kaul, C. Song, A. Kanthasamy, and A. G. Kanthasamy, "Pharmacological inhibition of neuronal NADPH oxidase protects against 1-methyl-4-phenylpyridinium (MPP+)-induced oxidative stress and apoptosis in mesencephalic dopaminergic neuronal cells," NeuroToxicology, vol. 28, no. 5, pp. 988-997, 2007.

[62] L. Qin, Y. Liu, T. Wang et al., "NADPH oxidase mediates lipopolysaccharide-induced neurotoxicity and proinflammatory gene expression in activated microglia," Journal of Biological Chemistry, vol. 279, no. 2, pp. 1415-1421, 2004.

[63] S. H. Huh, Y. C. Chung, Y. Piao et al., "Ethyl pyruvate rescues nigrostriatal dopaminergic neurons by regulating glial activation in a mouse model of Parkinson's disease," Journal of Immunology, vol. 187, no. 2, pp. 960-969, 2011.

[64] Q. Wang, K. D. Tompkins, A. Simonyi, R. J. Korthuis, A. Y. Sun, and G. Y. Sun, "Apocynin protects against global cerebral ischemia-reperfusion-induced oxidative stress and injury in the gerbil hippocampus," Brain Research, vol. 1090, no. 1, pp. 182-189, 2006.

[65] W. Lo, T. Bravo, V. Jadhav, E. Titova, J. H. Zhang, and J. Tang, "NADPH oxidase inhibition improves neurological outcomes in surgically-induced brain injury," Neuroscience Letters, vol. 414, no. 3, pp. 228-232, 2007.

[66] M. E. Lull, S. Levesque, M. J. Surace, and M. L. Block, "Chronic apocynin treatment attenuates beta amyloid plaque size and microglial number in hAPP(751) SL mice," PLoS One, vol. 6, no. 5, article e20153, 2011.

[67] X. N. Tang, B. Cairns, N. Cairns, and M. A. Yenari, "Apocynin improves outcome in experimental stroke with a narrow dose range," Neuroscience, vol. 154, no. 2, pp. 556-562, 2008.

[68] E. Titova, R. P. Ostrowski, L. C. Sowers, J. H. Zhang, and J. Tang, "Effects of apocynin and ethanol on intracerebral haemorrhage-induced brain injury in rats," Clinical and Experimental Pharmacology and Physiology, vol. 34, no. 9, pp. 845-850, 2007.

[69] R. L. Miller, G. Y. Sun, and A. Y. Sun, "Cytotoxicity of paraquat in microglial cells: involvement of $\mathrm{PKC} \delta$ - and ERK1/2-dependent NADPH oxidase," Brain Research, vol. 1167, no. 1, pp. 129-139, 2007.

[70] L. Qian, Z. Xu, W. Zhang, B. Wilson, J. S. Hong, and P. M. Flood, "Sinomenine, a natural dextrorotatory morphinan analog, is anti-inflammatory and neuroprotective through inhibition of microglial NADPH oxidase," Journal of Neuroinflammation, vol. 4, article no. 23, 2007.
[71] L. Ma and J. Zhou, "Dopamine promotes the survival of embryonic striatal cells: involvement of superoxide and endogenous NADPH oxidase," Neurochemical Research, vol. 31, no. 4, pp. 463-471, 2006.

[72] S. Nikolova, Y. S. Lee, Y. S. Lee, and J. A. Kim, "Rac1NADPH oxidase-regulated generation of reactive oxygen species mediates glutamate-induced apoptosis in SH-SY5Y human neuroblastoma cells," Free Radical Research, vol. 39, no. 12, pp. 1295-1304, 2005.

[73] M. G. Purisai, A. L. McCormack, S. Cumine, J. Li, M. Z. Isla, and D. A. Di Monte, "Microglial activation as a priming event leading to paraquat-induced dopaminergic cell degeneration," Neurobiology of Disease, vol. 25, no. 2, pp. 392-400, 2007.

[74] T. Yasuhara, T. Shingo, K. Kobayashi et al., "Neuroprotective effects of vascular endothelial growth factor (VEGF) upon dopaminergic neurons in a rat model of Parkinson's disease," European Journal of Neuroscience, vol. 19, no. 6, pp. 14941504, 2004.

[75] E. C. Hirsch, T. Breidert, E. Rousselet, S. Hunot, A. Hartmann, and P. P. Michel, "The role of glial reaction and inflammation in Parkinson's disease," Annals of the New York Academy of Sciences, vol. 991, pp. 214-228, 2003.

[76] H. M. Gao, F. Zhang, H. Zhou, W. Kam, B. Wilson, and J. S. Hong, "Neuroinflammation and $\alpha$-synuclein dysfunction potentiate each other, driving chronic progression of neurodegeneration in a mouse model of Parkinson's disease," Environmental Health Perspectives, vol. 119, no. 6, pp. 807814, 2011.

[77] Y. Liu, L. Qin, G. Li et al., "Dextromethorphan protects dopaminergic neurons against inflammation-mediated degeneration through inhibition of microglial activation," Journal of Pharmacology and Experimental Therapeutics, vol. 305, no. 1, pp. 212-218, 2003.

[78] G. Li, Y. Liu, N. S. Tzeng et al., "Protective effect of dextromethorphan against endotoxic shock in mice," Biochemical Pharmacology, vol. 69, no. 2, pp. 233-240, 2005.

[79] W. Zhang, T. Wang, L. Qin et al., "Neuroprotective effect of dextromethorphan in the MPTP Parkinson's disease model: role of NADPH oxidase," The FASEB Journal, vol. 18, no. 3, pp. 589-591, 2004.

[80] M. Ramanathan, S. Sivakumar, P. R. Anandvijayakumar, C. Saravanababu, and P. R. Pandian, "Neuroprotective evaluation of standardized extract of centella asciatica in monosodium glutamate treated rats," Indian Journal of Experimental Biology, vol. 45, no. 5, pp. 425-431, 2007.

[81] Y. Huo, P. Rangarajan, E. A. Ling, and S. T. Dheen, "Dexamethasone inhibits the Nox-dependent ROS production via suppression of MKP-1-dependent MAPK pathways in activated microglia," BMC Neuroscience, vol. 12, article 49, 2011.

[82] W. Zhang, E. J. Shin, T. Wang et al., "3-Hydroxymorphinan, a metabolite of dextromethorphan, protects nigrostriatal pathway against MPTP-elicited damage both in vivo and in vitro," FASEB Journal, vol. 20, no. 14, pp. 2496-2511, 2006.

[83] F. Zhang, J. S. Shi, H. Zhou, B. Wilson, J. S. Hong, and H. M. Gao, "Resveratrol protects dopamine neurons against lipopolysaccharide-induced neurotoxicity through its antiinflammatory actions," Molecular Pharmacology, vol. 78, no. 3, pp. 466-477, 2010. 
[84] R. Li, Y. G. Huang, D. Fang, and W. D. Le, “(-)-Epigallocatechin gallate inhibits lipopolysaccharide-induced microglial activation and protects against inflammation-mediated dopaminergic neuronal injury," Journal of Neuroscience Research, vol. 78, no. 5, pp. 723-731, 2004.

[85] L. Wang, S. Xu, X. Xu, and P. Chan, "(-)-epigallocatechin3-gallate protects SH-SY5Y cells against 6-OHDA-induced cell death through stat3 activation," Journal of Alzheimer's Disease, vol. 17, no. 2, pp. 295-304, 2009.

[86] H. Ruan, Y. Yang, X. Zhu, X. Wang, and R. Chen, "Neuroprotective effects of $( \pm)$-catechin against 1-methyl-4-phenyl1,2,3,6-tetrahydropyridine (MPTP)-induced dopaminergic neurotoxicity in mice," Neuroscience Letters, vol. 450, no. 2, pp. 152-157, 2009.

[87] A. Arimura, "Perspectives on pituitary adenylate cyclase activating polypeptide (PACAP) in the neuroendocrine, endocrine, and nervous systems," Japanese Journal of Physiology, vol. 48, no. 5, pp. 301-331, 1998.

[88] A. Arimura, A. Somogyvari-Vigh, C. Weill et al., "PACAP functions as a neurotrophic factor," Annals of the New York Academy of Sciences, vol. 739, pp. 228-243, 1994.

[89] T. Kozicz, S. Vigh, and A. Arimura, "Axon terminals containing PACAP- and VIP-immunoreactivity form synapses with CRF-immunoreactive neurons in the dorsolateral division of the bed nucleus of the stria terminalis in the rat," Brain Research, vol. 767, no. 1, pp. 109-119, 1997.

[90] D. E. Brenneman, J. M. Hauser, C. Y. Spong, and T. M. Phillips, "Chemokine release is associated with the protective action of PACAP-38 against HIV envelope protein neurotoxicity," Neuropeptides, vol. 36, no. 4, pp. 271-280, 2002.

[91] D. Uchida, A. Arimura, A. Somogyvári-Vigh, S. Shioda, and W. A. Banks, "Prevention of ischemia-induced death of hippocampal neurons by pituitary adenylate cyclase activating polypeptide," Brain Research, vol. 736, no. 1-2, pp. 280-286, 1996.

[92] S. Yang, J. Yang, Z. Yang et al., "Pituitary adenylate cyclaseactivating polypeptide (PACAP) 38 and PACAP4-6 are neuroprotective through inhibition of NADPH oxidase: potent regulators of microglia-mediated oxidative stress," Journal of Pharmacology and Experimental Therapeutics, vol. 319, no. 2, pp. 595-603, 2006.

[93] Q. G. Zhang, L. Raz, R. Wang et al., "Estrogen attenuates ischemic oxidative damage via an estrogen receptor $\alpha$-mediated inhibition of NADPH oxidase activation," Journal of Neuroscience, vol. 29, no. 44, pp. 13823-13836, 2009.

[94] K. M. Dhandapani and D. W. Brann, "Role of astrocytes in estrogen-mediated neuroprotection," Experimental Gerontology, vol. 42, no. 1-2, pp. 70-75, 2007.

[95] J. H. M. Prehn, V. P. Bindokas, C. J. Marcuccilli, S. Krajewski, J. C. Reed, and R. J. Miller, "Regulation of neuronal Bcl2 protein expression and calcium homeostasis by transforming growth factor type $\beta$ confers wide-ranging protection on rat hippocampal neurons," Proceedings of the National Academy of Sciences of the United States of America, vol. 91, no. 26, pp. 12599-12603, 1994.

[96] L. Qian and P. M. Flood, "Microglial cells and Parkinson's disease," Immunologic Research, vol. 41, no. 3, pp. 155-164, 2008.

[97] D. Zhang, X. Hu, S. J. Wei et al., "Squamosamide derivative FLZ protects dopaminergic neurons against inflammation-mediated neurodegeneration through the inhibition of NADPH oxidase activity," Journal of Neuroinflammation, vol. 5, article no. 21, 2008.
[98] S. Lanone, S. Bloc, R. Foresti et al., "Bilirubin decreases nos2 expression via inhibition of $\mathrm{NAD}(\mathrm{P}) \mathrm{H}$ oxidase: implications for protection against endotoxic shock in rats," FASEB Journal, vol. 19, no. 13, pp. 1890-1892, 2005.

[99] M. Santiago, M. C. Hernández-Romero, A. Machado, and J. Cano, "Zocor Forte (simvastatin) has a neuroprotective effect against LPS striatal dopaminergic terminals injury, whereas against $\mathrm{MPP}^{+}$does not," European Journal of Pharmacology, vol. 609, no. 1-3, pp. 58-64, 2009.

[100] K. Nakamichi, M. Saiki, H. Kitani et al., "Suppressive effect of simvastatin on interferon- $\beta$-induced expression of CC chemokine ligand 5 in microglia," Neuroscience Letters, vol. 407, no. 3, pp. 205-210, 2006.

[101] A. Cordle and G. Landreth, "3-Hydroxy-3-methylglutarylcoenzyme A reductase inhibitors attenuate $\beta$-amyloid-induced microglial inflammatory responses," Journal of Neuroscience, vol. 25, no. 2, pp. 299-307, 2005.

[102] J. Yan, Y. Xu, C. Zhu et al., "Simvastatin prevents dopaminergic neurodegeneration in experimental parkinsonian models: the association with anti-inflammatory responses," PLoS One, vol. 6, no. 6, article 20945, 2011.

[103] W. Chen, S. Pendyala, V. Natarajan, J. G. N. Garcia, and J. R. Jacobson, "Endothelial cell barrier protection by simvastatin: GTPase regulation and NADPH oxidase inhibition," American Journal of Physiology, Lung Cellular and Molecular Physiology, vol. 295, no. 4, pp. L575-L583, 2008.

[104] M. Thomas, W. D. Le, and J. Jankovic, "Minocycline and other tetracycline derivatives: a neuroprotective strategy in Parkinson's disease and Huntington's disease," Clinical Neuropharmacology, vol. 26, no. 1, pp. 18-23, 2003.

[105] D. C. Wu, V. Jackson-Lewis, M. Vila et al., "Blockade of microglial activation is neuroprotective in the 1-methyl-4phenyl-1,2,3,6-tetrahydropyridine mouse model of Parkinson disease," Journal of Neuroscience, vol. 22, no. 5, pp. 17631771, 2002.

[106] S. H. Choi, D. Y. Lee, E. S. Chung, Y. B. Hong, S. U. Kim, and B. K. Jin, "Inhibition of thrombin-induced microglial activation and NADPH oxidase by minocycline protects dopaminergic neurons in the substantia nigra in vivo," Journal of Neurochemistry, vol. 95, no. 6, pp. 1755-1765, 2005.

[107] D. K. Choi, S. Koppula, M. Choi, and K. Suk, "Recent developments in the inhibitors of neuroinflammation and neurodegeneration: inflammatory oxidative enzymes as a drug target," Expert Opinion on Therapeutic Patents, vol. 20, no. 11, pp. 1531-1546, 2010.

[108] P. Page, M. Orchard, L. Fioraso, and B. Mottiromi, "Pyrazolo pyridine derivatives as NADPH oxidase inhibitors," US 20100048560, 2010.

[109] P. Page, M. Orchard, L. Fioraso, and B. Mottiromi, “Tetrahydroindole derivatives as NADPH oxidase inhibitors," EP2139472A1, 2010.

[110] J. L. Arbiser, "Use of Imipramine blue and analogs thereof in treating cancers," US20100160296, 2010.

[111] K. I. Onda, K. Sato, F. Moritomo et al., "Quinolone derivatives," EP20080834496, 2010.

[112] M. S. Yamamoto and A. U. Saneyoshi, "NADH/NADPH oxidase inhibitors," JP2009007256, 2009.

[113] S. Przedborski and T. M. Dawson, "The role of nitric oxide in Parkinson's disease," Methods in Molecular Medicine, vol. 62, pp. 113-136, 2001.

[114] J. L. Dinerman, T. M. Dawson, M. J. Schell, A. Snowman, and S. H. Snyder, "Endothelial nitric oxide synthase localized to hippocampal pyramidal cells: implications for synaptic plasticity," Proceedings of the National Academy of Sciences of 
the United States of America, vol. 91, no. 10, pp. 4214-4218, 1994.

[115] S. Murphy, "Production of nitric oxide by glial cells: regulation and potential roles in the CNS," GLIA, vol. 29, no. 1, pp. $1-13,2000$.

[116] M. T. Heneka and D. L. Feinstein, "Expression and function of inducible nitric oxide synthase in neurons," Journal of Neuroimmunology, vol. 114, no. 1-2, pp. 8-18, 2001.

[117] A. Bal-Price and G. C. Brown, "Inflammatory neurodegeneration mediated by nitric oxide from activated gliainhibiting neuronal respiration, causing glutamate release and excitotoxicity," Journal of Neuroscience, vol. 21, no. 17, pp. 6480-6491, 2001.

[118] A. Bal-Price, A. Matthias, and G. C. Brown, "Stimulation of the NADPH oxidase in activated rat microglia removes nitric oxide but induces peroxynitrite production," Journal of Neurochemistry, vol. 80, no. 1, pp. 73-80, 2002.

[119] Y. Z. Ye, M. Strong, Z. Q. Huang, and J. S. Beckman, "Antibodies that recognize nitrotyrosine," Methods in Enzymology, vol. 269, pp. 201-209, 1996.

[120] D. Dexter, C. Carter, and F. Agid, "Lipid peroxidation as cause of nigral cell death in Parkinson's disease," Lancet, vol. 2, no. 8507, pp. 639-640, 1986.

[121] L. Broom, L. Marinova-Mutafchieva, M. Sadeghian, J. B. Davis, A. D. Medhurst, and D. T. Dexter, "Neuroprotection by the selective iNOS inhibitor GW274150 in a model of Parkinson disease," Free Radical Biology and Medicine, vol. 50, no. 5, pp. 633-640, 2011.

[122] C. Gahm, S. Holmin, P. N. Wiklund, L. Brundin, and T. Mathiesen, "Neuroprotection by selective inhibition of inducible nitric oxide synthase after experimental brain contusion," Journal of Neurotrauma, vol. 23, no. 9, pp. 1343-1354, 2006.

[123] M. J. D. Griffiths, M. Messent, R. J. MacAllister, and T. W. Evans, "Aminoguanidine selectively inhibits inducible nitric oxide synthase," British Journal of Pharmacology, vol. 110, no. 3, pp. 963-968, 1993.

[124] M. Sun, Y. Zhao, Y. Gu, and C. Xu, "Neuroprotective actions of aminoguanidine involve reduced the activation of calpain and caspase-3 in a rat model of stroke," Neurochemistry International, vol. 56, no. 4, pp. 634-641, 2010.

[125] D. J. Wolff and A. Lubeskie, "Aminoguanidine is an isoformselective, mechanism-based inactivator of nitric oxide synthase," Archives of Biochemistry and Biophysics, vol. 316, no. 1, pp. 290-301, 1995.

[126] D. Cash, J. S. Beech, R. C. Rayne, P. M. W. Bath, B. S. Meldrum, and S. C. R. Williams, "Neuroprotective effect of aminoguanidine on transient focal ischaemia in the rat brain," Brain Research, vol. 905, no. 1-2, pp. 91-103, 2001.

[127] J. Lu, S. Moochhala, M. Shirhan et al., "Neuroprotection by aminoguanidine after lateral fluid-percussive brain injury in rats: a combined magnetic resonance imaging, histopathologic and functional study," Neuropharmacology, vol. 44, no. 2, pp. 253-263, 2003.

[128] K. M. Cockroft, M. Meistrell, G. A. Zimmerman et al., "Cerebroprotective effects of aminoguanidine in a rodent model of stroke," Stroke, vol. 27, no. 8, pp. 1393-1398, 1996.

[129] I. D. Stevanović, M. D. Jovanović, M. Čolić et al., "The effect of aminoguanidine, an inducible nitric oxide synthase inhibitor, on $\mathrm{ALCL}_{3}$ toxicity in the rat hippocampus," Archives of Biological Sciences, vol. 62, no. 4, pp. 981-991, 2010.
[130] Z. J. Zhang, L. C.V. Cheang, M. W. Wang, and S. M.-Y. Lee, "Quercetin exerts a neuroprotective effect through inhibition of the iNOS/NO system and pro-inflammation gene expression in PC12 cells and in zebrafish," International Journal of Molecular Medicine, vol. 27, no. 2, pp. 195-203, 2011.

[131] Y. C. Lin, H. W. Uang, R. J. Lin, I. J. Chen, and Y. C. Lo, "Neuroprotective effects of glyceryl nonivamide against microglialike cells and 6-hydroxydopamine-induced neurotoxicity in SH-SY5Y human dopaminergic neuroblastoma cells," Journal of Pharmacology and Experimental Therapeutics, vol. 323, no. 3, pp. 877-887, 2007.

[132] K. Kotil, U. Kuscuoglu, M. Kirali, H. Uzun, M. Akçetin, and T. Bilge, "Investigation of the dose-dependent neuroprotective effects of agmatine in experimental spinal cord injury: a prospective randomized and placebo-control trial," Journal of Neurosurgery: Spine, vol. 4, no. 5, pp. 392-399, 2006.

[133] S. Condello, M. Curro, N. Ferlazzo, D. Caccamo, J. Satriano, and R. Ientile, "Agmatine effects on mitochondrial membrane potential andNF-kappaB activation protect against rotenone-induced cell damage in human neuronal-like SHSY5Y cells," Journal of Neurochemistry, vol. 116, no. 1, pp. 67-75, 2011.

[134] H. Kim, Y. S. Kim, S. Y. Kim, and K. Suk, "The plant flavonoid wogonin suppresses death of activated C6 rat glial cells by inhibiting nitric oxide production," Neuroscience Letters, vol. 309, no. 1, pp. 67-71, 2001.

[135] W. Chun, J. L. Hee, P. J. Kong et al., "Synthetic wogonin derivatives suppress lipopolysaccharide-induced nitric oxide production and hydrogen peroxide-induced cytotoxicity," Archives of Pharmacal Research, vol. 28, no. 2, pp. 216-219, 2005.

[136] R. Hattori, R. Inoue, K. Sase et al., "Preferential inhibition of inducible nitric oxide synthase by ebselen," European Journal of Pharmacology, Molecular Pharmacology Section, vol. 267, no. 2, pp. R1-R2, 1994.

[137] S. Moussaoui, M. C. Obinu, N. Daniel, M. Reibaud, V. Blanchard, and A. Imperato, "The antioxidant Ebselen prevents neurotoxicity and clinical symptoms in a primate model of Parkinson's disease," Experimental Neurology, vol. 166, no. 2, pp. 235-245, 2000.

[138] T. Dehmer, M. T. Heneka, M. Sastre, J. Dichgans, and J. B. Schulz, "Protection by pioglitazone in the MPTP model of Parkinson's disease correlates with $\mathrm{I} \kappa \mathrm{B} \alpha$ induction and block of NF $\kappa$ B and iNOS activation," Journal of Neurochemistry, vol. 88, no. 2, pp. 494-501, 2004.

[139] R. L. Hunter, N. Dragicevic, K. Seifert et al., "Inflammation induces mitochondrial dysfunction and dopaminergic neurodegeneration in the nigrostriatal system," Journal of Neurochemistry, vol. 100, no. 5, pp. 1375-1386, 2007.

[140] B. Xing, M. Liu, and G. Bing, "Neuroprotection with pioglitazone against LPS insult on dopaminergic neurons may be associated with its inhibition of NF- $\kappa \mathrm{B}$ and JNK activation and suppression of COX-2 activity," Journal of Neuroimmunology, vol. 192, no. 1-2, pp. 89-98, 2007.

[141] Y. C. Chung, S. R. Kim, and B. K. Jin, "Paroxetine prevents loss of nigrostriatal dopaminergic neurons by inhibiting brain inflammation and oxidative stress in an experimental model of Parkinson's disease," Journal of Immunology, vol. 185, no. 2, pp. 1230-1237, 2010.

[142] S. A. F. Thomas, U. Wolf-Rüdiger, H. Christian, L. Martin, K. B. R. Raimund, and E. Manfrid, "Imidazopyridine derivatives useful as iNOS inhibitors,” US7790710, 2010.

[143] N. T. J. Sharon, R. Sam, L. Guyan, C. Yulin, and M. Jean, "Coumarins as iNOS inhibitors," US 7538233, 2009. 
[144] N. M. O. Tadayoshi, K. Yasuo, W. Koji, and M. Takehito, "Sense Ologonucleotide capable of controlling the expression of iNOS and composition comprising the same," European Patent EP2031057, 2011.

[145] N. S.-J. K. Heonjoong and K. O. Hyun-Sil, "Pharmaceutical composition, healthfood composition and iNOS inhibitors, containing Theopederin derivatives," WO/2008/072937A1, 2008.

[146] I. Singh, "Inhibitors of nitric oxide synthase," US20090192120, 2009. 


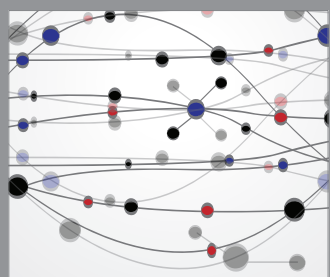

The Scientific World Journal
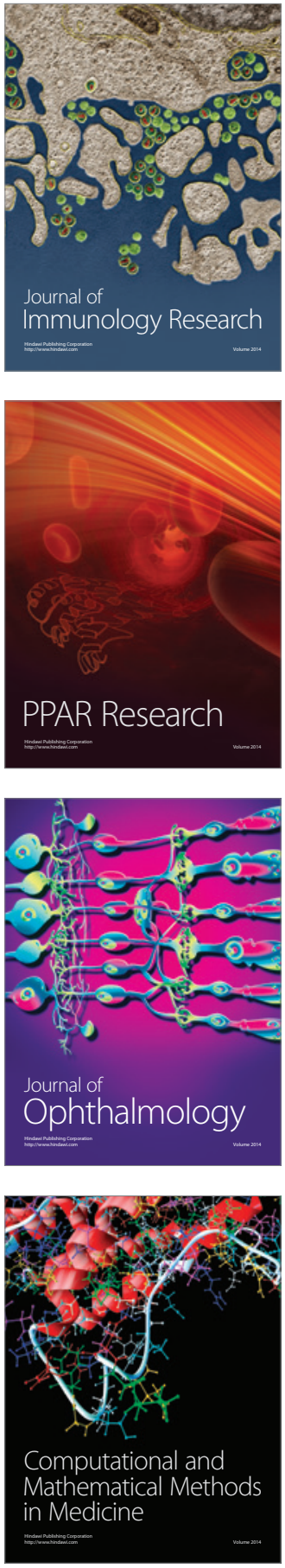

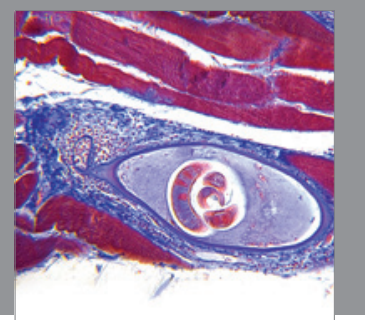

Gastroenterology

Research and Practice
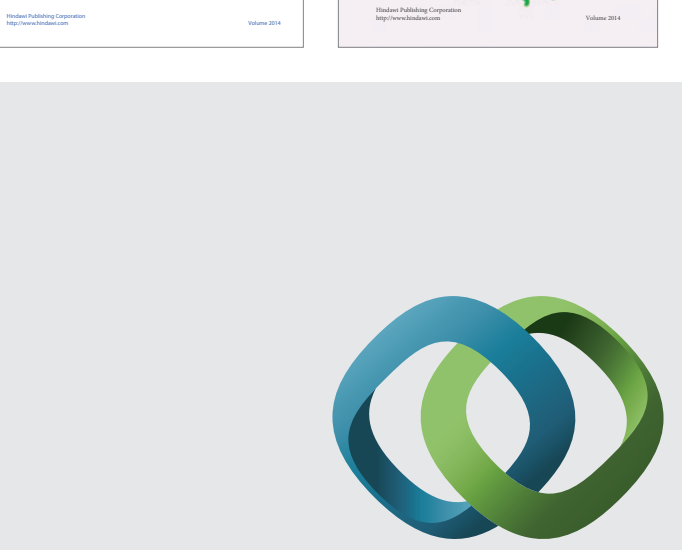

\section{Hindawi}

Submit your manuscripts at

http://www.hindawi.com
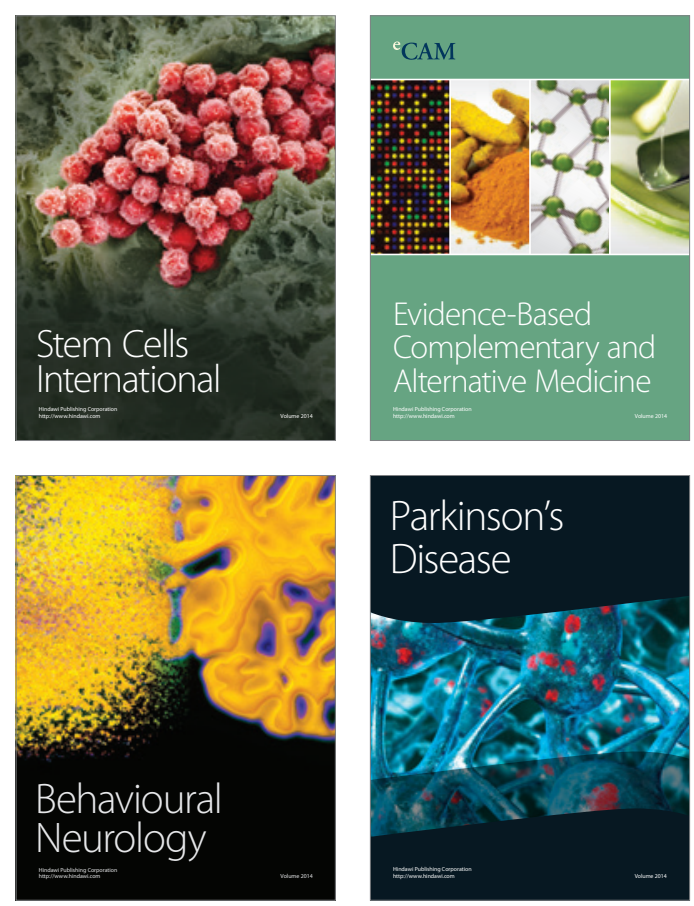

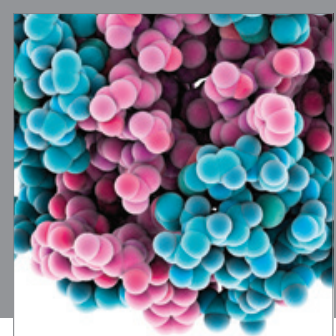

Journal of
Diabetes Research

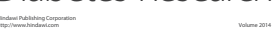

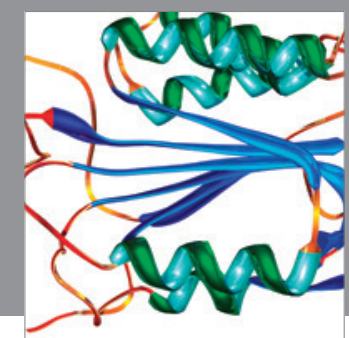

Disease Markers
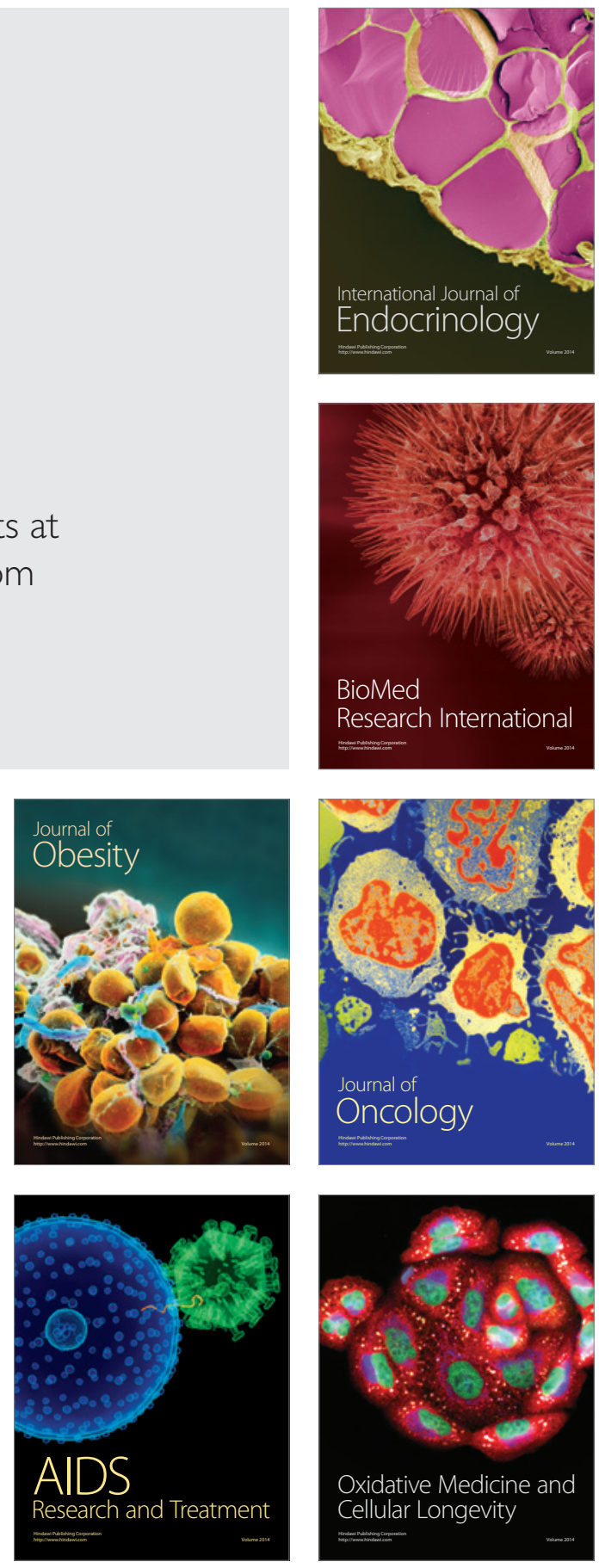